\title{
Erosional effects on runout of fast landslides, debris flows and avalanches: a numerical investigation
}

\author{
H. CHEN*, G. B. CROSTA $†$ and C. F. LEE $\ddagger$
}

\begin{abstract}
The mechanism of mass changes in debris transportation process is an important topic in the study of fast landslides, debris flows and avalanches. Basal erosion is recognised as a dynamic interaction between the original moving material and the entrained basal topsoil shearing along their non-slip contact surface. In this paper we propose a new concept of yield rate and establish the erosional relationship to bridge these two systems. A pertinent mathematical model and numerical implementation are formulated. Parametric numerical experiments are conducted to compare the erosional effects. The simulated results are consistent with available experimental and field observations. The influence of the involvement of the erosive material on runout behaviour and the global mobility of the moving material are elucidated. The proposed method is then employed to analyse a recent debris flow event in northern Italy. The excellent match to the field data gives it a plausible potential application to the analysis of this type of gravity-driven flow with significant erosion. Defined in a dimensionless form, the proposed yield rate can be estimated conveniently in general geotechnical practices.
\end{abstract}

KEYWORDS: erosion; landslides; numerical modelling and analysis; slopes
Le mécanisme des changements de masse dans le processus de transport des débris est un sujet important dans l'étude des glissements de terrain rapides, des coulées de débris et des avalanches. L'érosion basale est reconnue comme une interaction dynamique entre le matériau mouvant d'origine et le cisaillement du sol basal entraîné le long de leur surface de contact non glissante. Dans cet exposé, nous proposons un nouveau concept de taux d'écoulement et établissons la relation d'érosion pour relier ces deux systèmes. Nous formulons un modèle mathématique pertinent et une mise en oeuvre numérique. Nous menons des expériences numériques paramétriques pour comparer les effets d'érosion. Les résultats simulés correspondent aux données expérimentales disponibles et aux observations sur le terrain. Nous expliquons l'influence de la matière érosive sur le comportement d'écoulement ainsi que la mobilité globale de la matière mouvante. La méthode proposée est alors employée pour analyser un récent écoulement de débris dans le nord de l'Italie. L'excellente corrélation avec les données de terrain donne à cette étude une application potentielle plausible pour l'analyse de ce type d'écoulement dû à la pesanteur avec érosion significative. Défini dans une forme non dimensionnelle, le taux de glissement proposé peut être facilement estimé dans des pratiques géotechniques générales.

\section{INTRODUCTION}

Basal erosion or surficial material entrainment is frequently observed in the field on debris flows and avalanches during runouts. It embodies the process by which the underlying material is incorporated into the original moving material, resulting in a material volume enlargement of the moving system. Gully erosion and soil slips through the removal of topsoil carve out a low-relief erosional topography. Material can also be lost from the flow by deposition in the form of detached tails or lateral levees during runout. Mass changes in debris runout affect the behaviour of the flow system and the debris areal extents.

The mechanism of mass changes in debris transportation process is an interesting but sometimes controversial topic. Based on the equation of motion, Cannon \& Savage (1988) developed a lumped-mass model to consider the entrainment or subtracting material lost during debris movement, in which the existence of action-reaction pairs of forces propelling the slide mass along the runout surface was implied. Directly applied to gravity-driven flows, the mass-change processes automatically added or discarded momentum to

Manuscript received 2 August 2004; revised manuscript accepted 21 February 2006

Discussion on this paper closes on 1 December 2006, for further details see p. ii.

* Golder Associates Limited, Calgary, Alberta, Canada

† Dip Scienze Geologiche e Geotecnologie, Università degli Studi di Milano, Italy.

+ Department of Civil Engineering, University of Hong Kong, China. the flow system when material was gained or lost. Similarly, van Gassen \& Cruden (1989) explained the momentum transfer of debris deposition, and calculated runout distances of rockslides. However, Hungr (1990a, 1990b) pointed out that there were no such forces to propel the slide mass along the runout path; the velocity of mass expelled from the flow must be equal to zero. Otherwise, the huge magnitude of the implied thrust force for a typical debris flow surge moving with deposition would require a separated source of energy, which was not available in gravity-driven flows. Erlichson (1991) also indicated that the depositing material slowed by interaction with the bed rather than with the material that continues to move. The cited author further concluded that the equation of motion is not suitable to apply directly to the debris flow system.

Attention to soil erosion caused by rainfall and shallow overland flow has been largely brought to surface flow hydraulics (e.g. McNeil et al., 1996; Roberts et al., 1998; Zreik et al., 1998; Gabriels, 1999; Nearing et al., 1999). These experimental studies treated surface flow hydraulic conditions as the only factor influencing surface soil erosion. Physics-based mathematical modelling of soil loss from erosion under shallow water flow was the general method adopted (e.g. Foster \& Meyer, 1972; Winterwerp \& Kranenburg, 1997; Govindaraju, 1998; Tayfur, 2001), with a common hypothesis that a critical shear stress needs to be exceeded before erosion occurs, and when it is exceeded, soil erosion is proportional to the excess shear stress.

In debris flow study, most of the practical knowledge on erosion comes from empirical laws (e.g. Cannon, 1989; Takahashi et al., 1992). For engineering practice, channel 
debris yield rate $\left(\mathrm{m}^{3} / \mathrm{m}\right)$ was defined by Hungr et al. (1984) as the magnitude normalised by the length of channel (including any major tributaries) upstream of the depositional area, to the point(s) of origin. A constant yield rate, resulting from channel erodibility, was often used for preliminary estimation of debris flows/avalanches that entrain material during transportation (Cannon, 1989; Fannin \& Rollerson, 1993; Jakob et al., 1997; Fannin \& Wise, 2001) and for back-analysis of known events (Jakob et al., 2000). Crosta et al. (2006) simulated erosion and entrainment of loose material without imposing yield rates. Because of the non-linearity of rheology and the possible complexity of basal topography, the yield rates cannot be determined directly for prediction but through some empirical estimations.

Debris deposition was investigated as an inversed process of erosion (Hungr \& Evans, 1997), though they might be physically distinct. In our opinion, deposition is a kinematic variation within the debris body of one system. It occurs when the sediment load exceeds the transportation capacity, usually at the debris boundary, tail and lateral sides, when the depositing parts slow down, stretch and detach from the main flow and eventually stop. For significant erosion on natural ground, the central sliding mass shears part of the lateral material, leaving the latter as ridges (Corominas, 1995). Deposit may also occur at the tail of the main flow, when the momentum of that part of the debris vanishes. The material being deposited cannot take away its momentum from the reminder of the moving mass. The deposition process is different from that of entrainment because it occurs within the original moving system, whereas entrainment is a process involving new material coming from outside. The deposition process may be captured without introducing any additional constraint to an existing mathematical model of the moving body. From the computational point of view, methods in the Eulerian frame of reference (e.g. Sassa, 1988; Denlinger \& Iverson, 2001, 2004) can be readily applied without introducing any additional mechanism. The Lagrangian methods (e.g. Koch et al., 1994; Hungr, 1995; Chen \& Lee, 2000; McDougall \& Hungr, 2004) are also capable of simulating this phenomenon by breaking the connectivity of the detached cells from the main body. However, basal erosion is due to shearing along the contact surface between moving surges and underlying ground. It occurs between the two systems through dynamic action. An erosional relationship needs to be established in order to bridge/close the two systems.

\section{MATHEMATICAL FORMULATION}

Debris particles are assumed to be in close contact and moving relative to one another during runouts. The proposed model is defined in a rectangular Cartesian coordinate system $\mathbf{x}=(x, y, z)^{\mathrm{T}}$ with $z$ pointing upwards, opposite to the direction of gravity. Consider a vertical debris column with volume $V$ and horizontal projection area $A$ that are both functions of time $t$. Traced in the Lagrangian frame of reference for its trajectory $\mathbf{x}(t)$, such a debris column satisfies the fundamental principles of mass and momentum conservation in the context of continuum mechanics:

$$
\begin{aligned}
& \frac{\mathrm{d}}{\mathrm{d} t} \int_{V} \rho \mathrm{d} V=Q \\
& \frac{\mathrm{d}}{\mathrm{d} t} \int_{V} \rho \mathbf{u} \mathrm{d} V=\int_{V} \mathbf{F} \mathrm{d} V+\int_{S} \mathbf{T} \mathrm{d} S
\end{aligned}
$$

where $\mathrm{d} / \mathrm{d} t$ is the material derivative; $\mathbf{u}=(u, v, w)^{\mathrm{T}}$ is the velocity vector; $\rho$ is the bulk density of the moving material, and is assumed constant; $\mathbf{F}$ is the volumetric force density; and $\mathbf{T}$ is the shear traction force acting on the bounding surface $S(t)$ of the column. $Q$ is the mass flux rate of the eroded material through the contact surface with the bed $(Q$ $=0$ for non-erosion). It should be noted that the integrals are always over the same debris column.

Let $b(x, y, t)-z=0$ and $f(x, y, t)-z=0$ be the basal and free-surface elevation functions respectively. The vertical column height is thus $h=f-b$. Defining the gradient operator $\nabla=(\partial / \partial x, \partial / \partial y,-1)^{\mathrm{T}}$, the unit normal vector of the bed is

$$
\mathbf{n}=\frac{\nabla b}{|\nabla b|}=\frac{1}{q}\left(\frac{\partial b}{\partial x}, \frac{\partial b}{\partial y},-1\right)^{\mathrm{T}}
$$

where module $q=\left[(\partial b / \partial x)^{2}+(\partial b / \partial y)^{2}+1\right]^{1 / 2}$ is geometrically the inclination between the tangent plane of $b$ and the horizontal $x-y$ plane. By convention of the right-hand system, $\mathbf{n}$ is pointing outwards from the moving column. It is noted that the basal elevation is time dependent, owing to the removal of bed material.

Remarks should be made that the material derivative $\mathrm{d} / \mathrm{d} t$ can be generally evaluated through partial differentiation $\mathrm{d} / \mathrm{d} t=\partial / \partial t+\mathbf{u}_{\mathrm{R}} \cdot \nabla$, where $\mathbf{u}_{\mathrm{R}}$ is the velocity of flow particles relative to the moving reference window. In the Eulerian frame of reference, where the grid is fixed, $\mathbf{u}_{\mathrm{R}}=\mathbf{u}$. In the Lagrangian frame, where the characteristic curves are integrated, $\mathbf{u}_{\mathrm{R}}=\mathbf{0}$, and therefore the convective term vanishes. In the present study, the mesh translation is confined in the horizontal plane with $\mathbf{u}_{\mathrm{R}}=(0,0, w)^{\mathrm{T}}$. For example, because the free surface $f$ is a material boundary, then if we suppose no mass exchange through $f$, we have the conservation law $\mathrm{d} f / \mathrm{d} t=0$. With the spatial gradient $\nabla f=$ $(\partial f / \partial x, \partial f / \partial y,-1)^{\mathrm{T}}$, the kinematic boundary condition is $\partial f /$ $\partial t+\mathbf{u} \cdot \nabla f=0$ in the Eulerian frame but is $\partial f / \partial t=w$ in the Lagrangian frame.

The material derivative on the left-hand side of momentum equation (2) can be expressed into two parts:

$$
\frac{\mathrm{d}}{\mathrm{d} t} \int_{V} \rho \mathbf{u} \mathrm{d} V=\int_{V} \frac{\mathrm{d}(\rho \mathbf{u})}{\mathrm{d} t} \mathrm{~d} V+\int_{S} \rho \mathbf{u}\left(\mathbf{u}_{\mathrm{R}} \cdot \mathbf{n}\right) \mathrm{d} S
$$

where the last term is the momentum flux accompanying the change of volume that joins/leaves the original system. We assume that the erosion/deposition occurs only through the column contact area $A_{\mathrm{c}}$ with the bed. $A_{\mathrm{c}}$ can be readily computed from its horizontal projection $A$ via $A=\left(A_{c} \mathbf{n}\right) \cdot \mathbf{z}$ $=q^{-1} A_{\mathrm{c}}$ with $\mathbf{z}=(0,0,-1)^{\mathrm{T}}$. The mass-changing mechanism of bed lowering/elevating will be discussed in the next section. By virtue of $\mathrm{d} S=\mathrm{d} A_{c}=q \mathrm{~d} A$, equation (4) becomes

$$
\frac{\mathrm{d}}{\mathrm{d} t} \int_{V} \rho \mathbf{u} \mathrm{d} V=\int_{V} \frac{\mathrm{d}(\rho \mathbf{u})}{\mathrm{d} t} \mathrm{~d} V-\int_{A} \rho_{\mathrm{b}} \mathbf{u}_{\mathrm{b}} w_{\mathrm{b}} \mathrm{d} A
$$

where $\mathbf{u}_{\mathrm{b}}=\left(0,0, w_{\mathrm{b}}\right)^{\mathrm{T}}$ is the actual velocity at the bed, with $w_{\mathrm{b}}=\mathrm{d} b / \mathrm{d} t$ being the speed of bed lowering $\left(w_{\mathrm{b}}<0\right)$ or elevating $\left(w_{\mathrm{b}}>0\right)$ in the vertical direction. It is also noted that the flux term has changed the sign, and $q$ has been cancelled. The horizontal components of $\mathbf{u}_{\mathrm{b}}$ vanish owing to the non-slip boundary condition by which $b$ is defined. $\rho_{\mathrm{b}}$ is the bulk density of the bed material. In the present study, we deal with bed material that has the same bulk density as the sliding material, $\rho_{\mathrm{b}}=\rho$. However, it is possible that the entrapped material could have different rheological properties from the original source. Alluvial deposits or slope debris may be characterised by high water content, and they may control the mass behaviour if they remain entrapped at the base of the moving material. This 
could have a major effect on the final runout, but is subject to future investigations.

For vigorous debris flows, landslides, and rock and snow avalanches, the common geometrical property is that the spread is more predominant than the depth in scale, and translation is more significant than rotation in movement. It is thus justifiable to assume that the debris column remains vertical during displacement so that $\mathrm{d} V=h \mathrm{~d} A$ and, most importantly, any depth-averaged variable, in the sense of

$$
\bar{\Phi} h=\int_{b}^{f} \Phi \mathrm{d} z
$$

is reasonably representative of the simple variation of $\Phi=$ $\{\rho \mathbf{u} ; \mathbf{F}\}$ along the vertical direction. Using Leibnit's theorem on the depth integration, one also has

$$
\frac{\mathrm{d}(\bar{\Phi} h)}{\mathrm{d} t}=\frac{\mathrm{d}}{\mathrm{d} t} \int_{b}^{f} \Phi \mathrm{d} z=\int_{b}^{f} \frac{\mathrm{d} \Phi}{\mathrm{d} t} \mathrm{~d} z+\Phi_{\mathrm{f}} \frac{\mathrm{d} f}{\mathrm{~d} t}-\Phi_{\mathrm{b}} \frac{\mathrm{d} b}{\mathrm{~d} t}
$$

where $\Phi_{\mathrm{f}}$ and $\Phi_{\mathrm{b}}$ are the values of $\Phi$ taken at the free surface and the bed respectively. Subsequently, equation (5) reads (with $\Phi=\rho \mathbf{u}$ )

$$
\begin{aligned}
\frac{\mathrm{d}}{\mathrm{d} t} \int_{V} \rho \mathbf{u d} V & =\int_{A} \int_{b}^{f} \frac{\mathrm{d}(\rho \mathbf{u})}{\mathrm{d} t} \mathrm{~d} z \mathrm{~d} A-\int_{A} \rho \mathbf{u}_{\mathrm{b}} w_{\mathrm{b}} \mathrm{d} A \\
& =\int_{A}\left(\frac{\mathrm{d}(\rho \overline{\mathbf{u}} h)}{d \mathrm{t}}-\rho \mathbf{u}_{\mathrm{f}} \frac{\mathrm{d} f}{\mathrm{~d} t}+\rho \mathbf{u}_{\mathrm{b}} \frac{\mathrm{d} b}{\mathrm{~d} t}-\rho \mathbf{u}_{\mathrm{b}} w_{\mathrm{b}}\right) \mathrm{d} A
\end{aligned}
$$

where $\mathbf{u}_{\mathrm{f}}$ is the actual velocity at the free surface. As we do not consider any mass exchange at the free surface, $\mathrm{d} f / \mathrm{d} t$ $=0$. It is of interest that the last two terms in the above integrant cancel each other. Eventually, the momentum equation in $x-y$ plane simplifies as

$$
\int_{A} \frac{\mathrm{d}(\rho \overline{\mathbf{u}} h)}{\mathrm{d} t} \mathrm{~d} A=\int_{A} \overline{\mathbf{F}} h \mathrm{~d} A+\int_{A} \mathbf{T} \mathrm{d} A
$$

The velocities and volumetric forces hereinafter refer to the depth averaged unless otherwise stated, and the overbar is omitted for brevity.

\section{Basal erosion mechanisms and mass conservation}

The capability of basal erosion by debris flows heavily relies on the composition and structure of the underlying bed (the stratigraphic and textural details), as well as on basal shear stress acting on the bottom of the moving mass. When the erosive force from the moving material impact exceeds the resistance of the soil, basal detachment occurs. The stationary particles and/or the basal strip of material are scoured into the tangentially moving debris by lowering the non-slip basal surface, where the total momentum remains unchanged at the instant of erosion (Hungr, 1990a,b; Erlichson, 1991; Hungr \& Evans, 1997). Basal erosion caused by debris flows is a very complex dynamic process. For post-event field inspections, the likely depth of movement is largely from guesswork rather than from direct measurement. The estimation of erosion depth is especially difficult in channels with loose bed and banks. However, the volume of loose erodible material is assessed by an engineering geologist who can measure the surface area likely to be affected by erosion. Therefore, for engineering practice, especially for back-analysis of case histories, we propose the following concept of yield rate by extending that introduced by Hungr et al. (1984). For a typical debris column, we assume that the mass flux rate of erosion is proportional to the surface area $A_{\mathrm{c}}$ affected by erosion and the magnitude of the averaged debris velocity $|\mathbf{u}|$, so that

$$
Q=\int_{S} \rho\left(\mathbf{u}_{\mathrm{R}} \cdot \mathbf{n}\right) \mathrm{d} S=\int_{A} E \rho|\mathbf{u}| q \mathrm{~d} A
$$

where $E$ is the so-called yield rate, positive for entrainment and negative for deposition.

The original definition by Hungr et al. (1984) is in essence $Q=E \rho|\mathbf{u}|$, in which $E$ is interpreted as the volume of material eroded per unit length of the path, having the dimension $\left[\mathrm{m}^{3} / \mathrm{m}\right]$. It needs to be integrated over (or normalised with) the instantaneous total volume of mass if it is assigned to each discretised mass element in a dynamic analysis. In the present modification, however, $E$ is dimensionless and is defined as follows:

$E$ units of volume of material are to be eroded via a unit contact area as the debris travels a unit length of its path.

Intuitively, it may also be interpreted as follows:

A finite mass with a unit contact area and travelling a unit length in the course of sliding will result in a lowered basal surface by $E$ unit height (entrainment depth).

Equation (9) also implies that the bed, where by definition the non-slip condition holds, will be lowered vertically owing to the erosion $(E>0)$ at velocity $\mathbf{u}_{\mathrm{b}}=\left(0,0, w_{\mathrm{b}}\right)^{\mathrm{T}}$ with $w_{b}=-E q|\mathbf{u}|$. The static increase of debris depth at the instant of erosion will compensate the decrease of basal elevation while the contact area and the free surface remain unchanged. Projecting the bed lowering velocity to the normal direction $\mathbf{n}$, we have

$$
\mathbf{u}_{\mathrm{b}} \cdot \mathbf{n}=-E|\mathbf{u}|
$$

Therefore the proposed yield rate $E$ can also be explained as

the ratio between the normal bed lowering/scouring velocity and the average tangential velocity of sliding flow.

As will be shown in the following sections for the masschange landslide cases considered in the present study, $E$ is typically taken at an $O\left(10^{-3}\right)$. Although the deposit volume can reach a couple of times the initial volume, the bed topography change is still minor, because the eroded material is collected from the entire footprint area.

Attributed to the heterogeneous soil properties and the complex slope topography, an overall/equivalent yield rate can be determined only via hindcast analysis of known events. However, for preliminary estimates in geotechnical practice, we propose the following simple guideline.

$$
E \cong \alpha \frac{V_{\text {eroded }}}{A_{\text {effect }} d_{\text {centre }}}
$$

where $V_{\text {eroded }}$ is the total eroded volume, $A_{\text {effect }}$ is the total erosion-affected area, and $d_{\text {centre }}$ is the travel distance of the centre of mass, all of which are generally available from field inspection. The correction coefficient $\alpha(>1)$, to account for the system non-linearity, will be calibrated later. For example, we shall apply this guideline below for the Bianzone debris flow in the Valtellina area, northern Italy.

\section{Force analysis and momentum conservation}

Referring to the moving column as shown in Fig. 1 (simplified in the $x-z$ plane), the volumetric force in equation (2) consists of $\mathbf{F}=\mathbf{N}+\mathbf{P}+\mathbf{G}$ with the basal normal force $\mathbf{N}$, the net intercolumn force $\mathbf{P}$ and the gravity force G. The shear traction force $\mathbf{T}$ is the basal friction force acting on the contact surface $A_{\mathrm{c}}$. Equation (8) is for the 


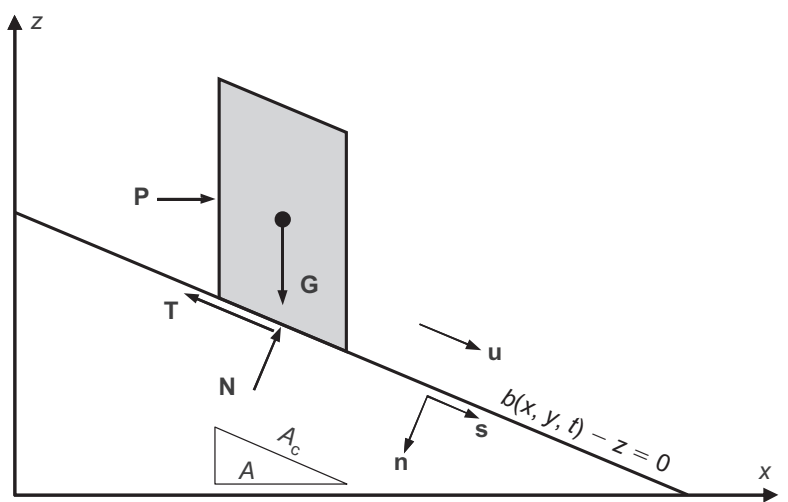

Fig. 1. Diagram of forces acting on a typical debris column (simplified in the $x-z$ plane)

horizontal components $(u, v)$; the vertical velocity $w$ is dependent on the sliding constraint along the normal direction of the bed. Let $\mathbf{u}_{\mathrm{f}}=\left(0,0, w_{\mathrm{f}}\right)^{\mathrm{T}}$ be the free-surface elevation velocity in the Lagrangian viewing window translating at the averaged velocity $(u, v)^{\mathrm{T}}$, where $w_{\mathrm{f}}=\partial f / \partial t$. Kinematic constraint requires that the normal velocity of the moving material shall be bounded by the movement of the upper and lower surfaces:

$$
\mathbf{u} \cdot \mathbf{n}=\frac{1}{2}\left(\mathbf{u}_{\mathrm{b}}+\mathbf{u}_{\mathrm{f}}\right) \cdot \mathbf{n}
$$

where it has been assumed that the normal direction of the free surface is parallel to the bed normal $\mathbf{n}$ owing to the shallowness of the debris. It is also noted that $\mathbf{u} \cdot \mathbf{n}=0$ for debris moving uniformly along a non-erosional slope. Subsequently, equation (12) yields

$$
w=u \frac{\partial b}{\partial x}+v \frac{\partial b}{\partial y}+\frac{1}{2}\left(w_{\mathrm{b}}+w_{\mathrm{f}}\right)
$$

Let the gravity force $\mathbf{G}=(0,0,-\rho g)^{\mathrm{T}}$. Directly applying Newton's second law along the normal direction of the slope n, we have

$$
\left(\rho \frac{\mathrm{d} \mathbf{u}}{\mathrm{d} t} \cdot \mathbf{n}\right) \mathbf{n}=\mathbf{N}+(\mathbf{G} \cdot \mathbf{n}) \mathbf{n}+(\mathbf{P} \cdot \mathbf{n}) \mathbf{n}
$$

We assume that the normal component of the net intercolumn force associated with changes in the normal momentum, $(\mathbf{P} \cdot \mathbf{n}) \mathbf{n}$, is negligible relative to the static weight. As pointed out by Denlinger \& Iverson (2004), this assumption has been made either explicitly or implicitly in all shallow flow theories. Consequently, equation (14) is simplified to

$$
\mathbf{N} \cong-(\mathbf{G} \cdot \mathbf{n}) \mathbf{n}+\left(\rho \frac{\mathrm{d} \mathbf{u}}{\mathrm{d} t} \cdot \mathbf{n}\right) \mathbf{n}=-\left(\mathbf{G}^{*} \cdot \mathbf{n}\right) \mathbf{n}
$$

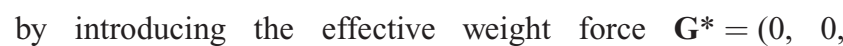
$\left.-\rho g^{*}\right)^{\mathrm{T}}$ with $g^{*}=g+\Delta g$, where

$$
\Delta g=-\frac{\mathrm{d} \mathbf{u}}{\mathrm{d} t} \cdot \mathbf{n}=\frac{\mathrm{d} w}{\mathrm{~d} t}-\frac{\mathrm{d} u}{\mathrm{~d} t} \frac{\partial b}{\partial x}-\frac{\mathrm{d} v}{\mathrm{~d} t} \frac{\partial b}{\partial y}
$$

Implicated by

$$
\frac{\mathrm{d} \mathbf{u}}{\mathrm{d} t} \cdot \mathbf{n}=\frac{\mathrm{d}(\mathbf{u} \cdot \mathbf{n})}{\mathrm{d} t}-\mathbf{u} \cdot \frac{\mathrm{d} \mathbf{n}}{\mathrm{d} t}
$$

$\Delta g$ apparently accounts for the local topographic change (the centripetal effect) through the term $-\mathbf{u} \cdot \mathrm{d} \mathbf{n} / \mathrm{d} t$, and the non-uniform lowering of the bed or accumulation of the debris depth (the lost/gained-weight effect) through the term $d(\mathbf{u} \cdot \mathbf{n}) / \mathrm{d} t$. Inspired by Denlinger \& Iverson (2004), but appearing in a different form (in the Lagrangian frame), $\Delta g$ is used to construct the basal normal force. By avoiding direct computation of the second-order differentiation for basal curvature, $\Delta g$ can be evaluated conveniently from equation (16) through the inner product of accelerations and basal gradients. Detailed comments are presented in Appendix 1 .

Let the direction of movement $\xi=\left(\xi_{x}, \xi_{y}\right)^{\mathrm{T}} \|(u, v)^{\mathrm{T}}$ and its transversal direction $\boldsymbol{\eta}=\left(\eta_{x}, \eta_{y}\right)^{\mathrm{T}}=\left(\xi_{y},-\xi_{x}\right)^{\mathrm{T}}$ in the horizontal plane. Assuming that the internal principal stresses are aligned locally with $\boldsymbol{\xi}$ and $\boldsymbol{\eta}$ with dominant deformation in $\xi$ (Gray et al., 1999), and the lateral normal stresses are proportional to the apparent weight per unit area (Savage \& Hutter, 1989; Denlinger \& Iverson, 2001), we approximate the net intercolumn force by

$$
\begin{aligned}
\mathbf{P} & =P_{\xi} \boldsymbol{\xi}+P_{\eta} \boldsymbol{\eta} \\
& =-k_{\xi}\left[\nabla\left(h \rho g^{*}\right) \cdot \boldsymbol{\xi}\right] \boldsymbol{\xi}-k_{\eta}\left[\nabla\left(h \rho g^{*}\right) \cdot \boldsymbol{\eta}\right] \boldsymbol{\eta}
\end{aligned}
$$

where $\left(k_{\xi}, k_{\eta}\right)$ are the earth pressure coefficients with respect to the local coordinates $\left(k_{\xi \eta}=k_{\eta \xi}=0\right)$, and are taken from the switch functions:

$$
k_{\xi}=\left\{\begin{array}{ll}
k_{\xi}^{\text {act }} & \left(\varepsilon_{\xi}>0\right) \\
1 & \left(\varepsilon_{\xi}=0\right), \\
k_{\xi}^{\text {pas }} & \left(\varepsilon_{\xi}<0\right)
\end{array} \quad k_{\eta}= \begin{cases}k_{\eta}^{\text {act }} & \left(\varepsilon_{\eta}>0\right) \\
1 & \left(\varepsilon_{\eta}=0\right) \\
k_{\eta}^{\text {pas }} & \left(\varepsilon_{\eta}<0\right)\end{cases}\right.
$$

Here, $\left(\varepsilon_{\xi}, \varepsilon_{\eta}\right)$ are the rates of strain along $\xi$ and $\boldsymbol{\eta}$, convertible from the rate-of-strain tensor $\varepsilon=\frac{1}{2}\left[\nabla \mathbf{u}+(\nabla \mathbf{u})^{\mathrm{T}}\right]$ by projecting along the assumed principal directions:

$$
\begin{aligned}
\varepsilon_{\xi} & =\boldsymbol{\xi}^{\mathrm{T}} \cdot \boldsymbol{\varepsilon} \cdot \boldsymbol{\xi}=\varepsilon_{x x} \xi_{x}^{2}+2 \varepsilon_{x y} \xi_{x} \xi_{y}+\varepsilon_{y y} \xi_{y}^{2} \\
\varepsilon_{\eta} & =\boldsymbol{\eta}^{\mathrm{T}} \cdot \boldsymbol{\varepsilon} \cdot \boldsymbol{\eta}=\varepsilon_{x x} \xi_{y}^{2}-2 \varepsilon_{x y} \xi_{x} \xi_{y}+\varepsilon_{y y} \xi_{x}^{2}
\end{aligned}
$$

In terms of the global coordinates, the frame-invariant equation (18), can be rewritten as

$$
\mathbf{P}=-\mathbf{k} \cdot \nabla\left(h \rho g^{*}\right)
$$

where $\mathbf{k}$ appears in the form of an anisotropic set of coefficients $\left(k_{x y}=k_{y x}\right)$ :

$$
\mathbf{k}=\left(\begin{array}{cc}
k_{x x} & k_{y x} \\
k_{x y} & k_{y y}
\end{array}\right)=\left(\begin{array}{cc}
k_{\xi} \xi_{x}^{2}+k_{\eta} \xi_{y}^{2} & \left(k_{\xi}-k_{\eta}\right) \xi_{x} \xi_{y} \\
\left(k_{\xi}-k_{\eta}\right) \xi_{x} \xi_{y} & k_{\xi} \xi_{y}^{2}+k_{\eta} \xi_{x}^{2}
\end{array}\right)
$$

By means of a standard Mohr diagram, the lateral earth pressure coefficients in active or passive state $\left(k^{\mathrm{act} / \mathrm{pas}}\right)$ are developed by geometrical considerations of the dilatating or compressing behaviour of the moving material columns (Koch et al., 1994):

$$
\begin{aligned}
& k_{\xi}^{\text {pas } / \text { act }}=2 \frac{1 \pm\left[1-\cos ^{2} \phi\left(1+\mu^{2}\right)\right]^{1 / 2}}{\cos ^{2} \phi}-1 \\
& k_{\eta}^{\text {pas } / \text { act }}=\frac{1}{2}\left\{k_{\xi}+1 \pm\left[\left(k_{\xi}-1\right)^{2}+4 \mu^{2}\right]^{1 / 2}\right\}
\end{aligned}
$$

where $\mu$ is the ratio between the basal shear force and the basal normal force, and $\phi$ is the internal friction angle. The switch between the active and passive values can be numerically fine-tuned in a manner of incremental rates of strain (Hungr, 1995). In a recent study by Denlinger \& Iverson (2004), the three-dimensional full stresses are integrated up to the yield conditions after introducing an isotropic matrix of elastic coefficients. They have reported improved resolution of Coulomb stresses due to the continuous variations of Rankine earth pressure ratios.

The shear force $\mathbf{T}$ opposite to the moving direction $\mathbf{s} \| \mathbf{u}$ is a function of different rheological constitutive relationships. 
Voellmy rheology has been widely used in modelling granular flows and rock avalanches (e.g. Korner, 1976; McLellan \& Kaiser, 1984; Hungr \& Evans, 1997; Rickenmann \& Koch, 1997; Chen \& Lee, 2000, 2003; Crosta et al., 2004). The basal shear force $\mathbf{T}$ per unit area in the Voellmy rheology reads

$$
\mathbf{T}=-\left(\mu^{\prime}|\mathbf{N}| h+\gamma \frac{|\mathbf{u}|^{2}}{\zeta}\right) \mathbf{s}
$$

where $\gamma$ is the unit weight and $\zeta$ is a turbulence coefficient with units $\left[\mathrm{m} / \mathrm{s}^{2}\right]$. The effective dynamic friction coefficient is written as $\mu^{\prime}=\left(1-r_{\mathrm{u}}\right) \tan \delta$, with $\delta$ being the dynamic basal friction angle that can be displacement dependent in simulating the decay of strength from peak to residual. The pore pressure ratio $r_{\mathrm{u}}$ is brought in to account for the pore pressure effect (McLellan \& Kaiser, 1984). It can reach relatively high values during rapid and intense loadings, and can vary both spatially and temporally. When the turbulence effect is not considered $(\xi \rightarrow \infty)$, Voellmy rheology reduces to friction rheology.

It follows from equations (15), (21) and (25) that the dimensionless form of the horizontal momentum equation (8) becomes

$$
\begin{aligned}
& \int_{A} \frac{\mathrm{d}(\mathbf{u} h)}{\mathrm{d} t} \mathrm{~d} A=-\int_{A} {\left[\left(\mathbf{g}^{\prime} \cdot \mathbf{n}\right)\left(\mathbf{n}+\mu^{\prime} \mathbf{s}\right)+\frac{|\mathbf{u}|^{2}}{h \zeta^{\prime}} \mathbf{s}\right.} \\
&\left.+\mathbf{k} \cdot \nabla\left(h g^{\prime}\right)\right] h \mathrm{~d} A
\end{aligned}
$$

where the variables have already been scaled by $L,(g L)^{1 / 2}$ and $(L / g)^{1 / 2}$ as the reference length, velocity and time, respectively, resulting in a unity Froude number. $\mathbf{g}^{\prime}=-\left(0,0, g^{\prime}\right)^{\mathrm{T}}$ is the effective weight direction vector $\left(g^{\prime}=1+\Delta g\right)$. The dimensionless turbulence coefficient is thus $\zeta^{\prime}=\zeta / g$. The primes on $\mathbf{u}, h, A$ and $t$ have been omitted.

\section{Solution strategy and numerical implementation}

As is customary with finite element formulation in the present study, the activated debris is discretised with a finite number of quadrilateral elements (vertical columns) contacting each other that are free to deform in a Lagrangian moving frame. The variables at time level $n$ refer to

$$
\boldsymbol{\Phi}^{n}=\boldsymbol{\Phi}\left(\mathbf{x}^{n}\right)=\boldsymbol{\Phi}\left(\mathbf{x}\left(t^{n}\right)\right) \quad \boldsymbol{\Phi}=\{\mathbf{u}, h, b\}
$$

The debris columns deform, following the characteristic paths of element vertices in the horizontal plane $(x-y)$ :

$$
\mathbf{x}^{n+1}=\mathbf{x}^{n}+\int_{t^{n}}^{t^{n+1}} \mathbf{u d} t
$$

where the velocities $(u, v)$ are solved by equation (26):

$$
\begin{aligned}
\int_{A} \frac{\mathrm{d}(u h)}{\mathrm{d} t} \mathrm{~d} A=-\int_{A} & {\left[\frac{g^{\prime}}{q^{2}} \frac{\partial b}{\partial x}+k_{x x} \frac{\partial\left(h g^{\prime}\right)}{\partial x}+k_{y x} \frac{\partial\left(h g^{\prime}\right)}{\partial y}\right.} \\
+ & \left.\frac{u}{|\mathbf{u}|}\left(\frac{g^{\prime}}{q} \mu^{\prime}+\frac{|\mathbf{u}|^{2}}{h \varsigma^{\prime}}\right)\right] h \mathrm{~d} A \\
\int_{A} \frac{\mathrm{d}(v h)}{\mathrm{d} t} \mathrm{~d} A=-\int_{A} & {\left[\frac{g^{\prime}}{q^{2}} \frac{\partial b}{\partial y}+k_{x y} \frac{\partial\left(h g^{\prime}\right)}{\partial x}+k_{y y} \frac{\partial\left(h g^{\prime}\right)}{\partial y}\right.} \\
+ & \left.\frac{v}{|\mathbf{u}|}\left(\frac{g^{\prime}}{q} \mu^{\prime}+\frac{|\mathbf{u}|^{2}}{h \varsigma^{\prime}}\right)\right] h \mathrm{~d} A
\end{aligned}
$$

while $w$ is dependent from equation (13). The debris depth $h$, vanishing at the debris margins, is then redistributed in the sense of least squares using the element volume updated via the genuine mass conservation equation (1).

It is worthwhile mentioning that, in our numerical implementation, mass conservation is strictly satisfied unless mesh projection (rezoning) is automatically activated by the builtin mesh quality monitor. Among different mesh-smoothing techniques, without changing the connectivity we found that the boundary-fitted partial differential transformation solved on the initial high-quality mesh is the most robust. The reader is referred to Chen \& Lee $(2000,2002,2003)$ for details of the finite element idealisation. The model validations therein include comparisons with available data from experiments and field cases that have been analysed by the widely used model of Hungr (1995) using the same rheological closures and parameters.

Here, we perform one more comparison with the laboratory experiment by Gray et al. (1999) for channellised granular flows using quartz chips (mean diameter 2-4 mm). The internal friction angle is $\phi=40^{\circ}$ and basal friction angle is $\delta=30^{\circ}$ as measured. The initial debris at rest has a maximum height of $22.0 \mathrm{~cm}$ and an elliptical projection on the horizontal plane with transversal semi-major $30.0 \mathrm{~cm}$ and semi-minor $24.5 \mathrm{~cm}$ along the major descending direction. Fig. 2 shows snapshots of the shapes and depth distributions of the released material rushing down the parabolic crossslope topography, with the initial shape shown in Fig. 2(d). The present model reproduces the front locations extremely well. Meanwhile, we are also able to obtain the typical bullet-shaped deposition with well-matched lateral width. Nevertheless, there are two major discrepancies. One is the noticeable slow motion of the tail, as also observed by Gray et al. (1999) from their simulations. A possible explanation is that the tail becomes very thin $(1-2 \mathrm{~cm})$, and the grain size effect starts playing a role. The other discrepancy is the final deposition shape, although the depth distribution is very similar. A small portion of the rear part of the material remains on the transition zone, slightly higher than the experimental measurement. We used a linear transition, $x \in$ $[175,215] \mathrm{cm}$, to connect the chute and the runout zone, which is not described in the cited paper and might be different from the actual experimental set-up.

During the deposition stage, when the front has completely lost its momentum while the main body is still sliding down the slope, an oblique, sharp surface wave forms in the middle of deposition and propagates backwards (see Fig. 2(c)). As the present model is formulated on the Lagrangian moving mesh, such a shock wave is well preserved until numerical instability arises, and is then smeared by the activated mesh rezoning. As in most of the dynamic models for landslide mobility simulations, we have not yet implemented any special treatment for capturing shock. In our future work, the front-tracking technique as recently developed by Tai et al. (2002) might be adopted. However, it may remain challenging in the quasi-three-dimensional problems, especially on unstructured meshes.

\section{NUMERICAL EXPERIMENTS}

In order to evaluate the erosional effects on debris runout behaviour, we set up the following numerical experiments with different basal topographies (unconfined and channellised), rheologic formulae (friction and Voellmy) and yield rates (non-erosion and erosion). The geometric configurations are designed as an inclined slope $\left(40^{\circ}\right)$ and a horizontal runout zone connected with a linear transition zone. The $x-$ $y$ plane of the Cartesian coordinate sits on the horizontal zone with the origin coinciding with the projection of the 


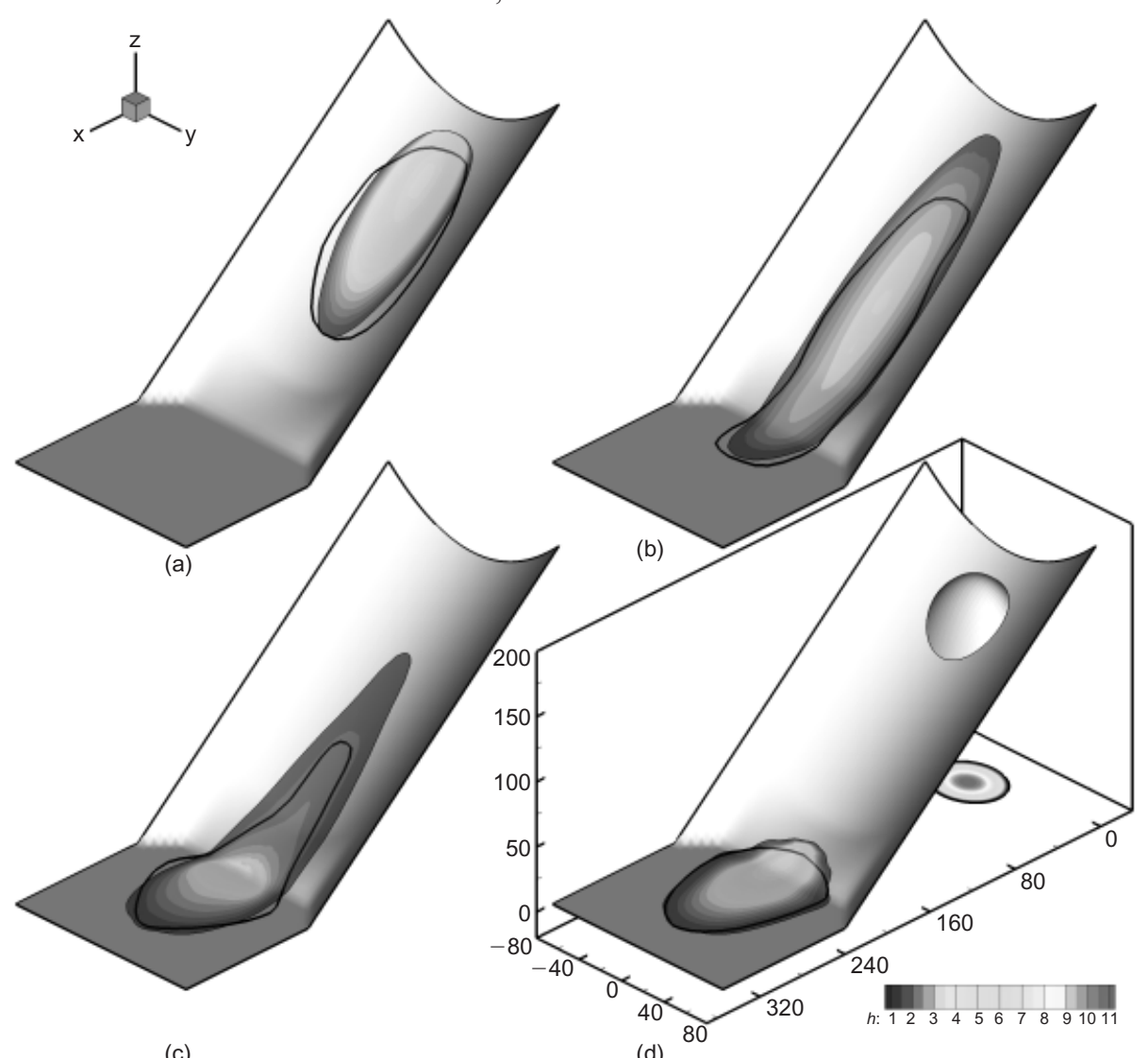

(c)

(d)

Fig. 2. Granular material sliding on a partially confined slope: (a) $t=0 \cdot 5$; (b) $t=1 \cdot 0$; (c) $t=$ 1.5; (d) $t=2 \cdot 0$ (contours, computed debris depth, $\Delta h=1 \mathrm{~cm}$; thick lines, measured debris margins from Gray et al., 1999)

centre of mass of the initial material. The $x$-axis is aligned with the steepest descent of the slope surface (see Fig. 3). Two basal topographies are considered for the slope: an inclined plane (series A), and one on which a shallow channel is superposed with a cosine cross-slope profile (series B) that laterally constrains the material movement. All tests begin with the same amount of material resting on the upper section of the inclined zone. The initial mass is a spherical cap whose projection on the $x-y$ plane is a circle with radius $R$. The maximum height of the initial mass is $H$ $=\frac{1}{4} R$, which gives an initial volume $V_{0}=\frac{1}{6} \pi H\left(3 R^{2}+H^{2}\right) \cong$ $0 \cdot 4 R^{3}$. For series $\mathrm{B}$, the channel shapes as

$$
z=\frac{1}{2} R \cos (\pi y / 2 R) \quad \text { for }|y|<2 R
$$

For both cases, the slope projected on the $x$-axis lies in the range $x<9 R$, and the horizontal runout zone is $x>11 R$.

The granular material is assumed to have an internal friction angle $\phi=40^{\circ}$. In friction rheology, the dynamic basal friction angle is taken as $\delta=30^{\circ}$. In Voellmy rheology, the effective dynamic friction coefficient $\mu^{\prime}=$ 0.45 and the dimensionless turbulent coefficient $\xi^{\prime}=100$. Three different yield rates are considered: $E=0,3 \times 10^{-3}$ and $7 \times 10^{-3}$. The unstructured mesh of the initial mass is shown in the inset in Fig. 3, where the front and rear are intentionally refined. The convergence tests conducted ensure that the resolution of discretisation is sufficient to reveal the most relevant flow features.

\section{Results of friction rheology}

For unconfined flows (series A) under different yield rates, the boundary profiles of the moving material projected on the $x-y$ plane are shown in Fig. 4(a) for the indicated time instants. It can be seen that, once the cap-shaped material is released, it accelerates downwards rapidly on the inclined flat plane without side constraint, spreading laterally as it goes. The profile reshapes from a circle to a teardrop with a blunt front and a pointed tail. As the leading edge passes the transition zone and enters the horizontal zone, the front rapidly decelerates while the tail still pushes forward. As the mass comes to rest, the profile assumes a horseshoe form. The non-erosional result in Fig. 4(a1) is very typical, and qualitatively correlates with the physical experiments of Koch et al. (1994) performed on quartz granules with internal friction angle of $39^{\circ}$ and basal friction angle of $29^{\circ}$.

The same amount of material is released and channellised by the cosine cross-slope profile as it accelerates down (series B). Fig. 4(b) depicts the projected margin contours on the horizontal plane for the indicated time instants. Originally shaped as a circle, the profile elongates along the channel, gradually reforming as a tadpole-like body. The sidewise spreading is small all the time. The moving pattern along the inclined channel does not change significantly, although the yield rates are different. When entering the horizontal runout zone, longitudinal elongation is still relatively dominant, although there is no side constraint, and a higher yield rate corresponds to wider lateral spreading. It is noted that the non-erosional results in Fig. 4(b1), including the bullet-form deposition, bear a remarkable resemblance to the experiments by Gray et al. (1999) for channellised granular flows using quartz chips (mean diameter 2-4 mm) with internal friction angle of $40^{\circ}$ and basal friction angle of $30^{\circ}$.

Debris thickness distributions in the deposition zone are also given in Fig. 4. The deposits all show substantial 


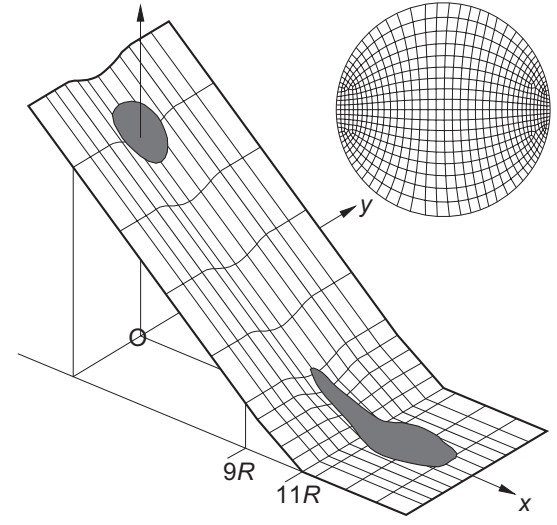

Fig. 3. Set-up of the numerical experiments (shown for the series $B$ geometry)

thickening near the tails, with a forward thin front. Entrainment considerably influences the deposit profiles. If a large amount of material is entrained, the front of the unconfined flow (series A) is concave in shape whereas that of the channellised flow (series B) is blunter. For the same series of flows, the higher the yield rate, the further the front reaches. It is apparent that basal topography also affects the deposit profile. Interestingly, the centre of mass of the deposit is not situated at its maximum thickness but ahead of it. For all cases, the centres of mass (reflecting global mobility) are nearly the same, although the front of the channellised flow (series B) propagates further than that of the unconfined flow (series A). This is meaningful in downslope zonation management, in that the reach of the front of a debris flow is of more concern than that of the centre of mass of the deposit.

The debris profiles are probed longitudinally along the centre of the descending axis of the flow (Fig. 5). For clarity, the depth of the displacing material has been exaggerated by 10 times in the plots. Initially, the mobilised material is relatively thicker in the tail and thinner in the front. With concomitant downslope movement the average depth decreases gradually, although there is additional material involved from time to time. When the material begins to dam the deposition area, the material depth progressively increases owing to the development of the cumulative total volume. The material eventually reshapes its relatively thick body and its thin proximal front.

The variations of some kinematic parameters during runout are recorded in Fig. 6, in which Figs 6(a1) and 6(b1) show the time histories of dimensionless mean velocity. It can be seen that, for both unconfined and channellised flows, the variation of mean velocity during runout is almost unaffected by the difference of yield rate. In order words, using friction rheology, the entrainment of even a large quantity of material does not significantly alter the global mobility of the slide. It is also seen that the global mobility of the unconfined flows is only slightly higher than that of the channellised flows. We shall try to interpret these phenomena in a later section. The volumetric variation with time in Figs 6(a2) and 6(b2) exhibits the mass accumulation process. Under the same geometric condition, the flow sweeps more material with respect to a higher yield rate. With the same yield rate, the unconfined flows sweep more material than the channellised ones. This suggests that the basal topography plays a significant role in the erosion process. Figs 6(a3) and 6(b3) give the variations of debris front velocity. Regardless of the differences of yield rate or geometric condition of runout path, the variation patterns of the front velocity are very similar. The frontal speed reaches peak before the moving material enters the transition zone. It decreases moderately in the transition zone, followed by a quick reduction of speed in the horizontal zone. Moreover, a larger value of front velocity always relates to a higher yield rate.

\section{Results of the Voellmy rheology}

Figure 7(a) gives the time sequence of the margins of the unconfined flows (series A). The margin changes from initially a circle to a teardrop shape with a wider, blunt front but a concave, narrow end, which may be caused by the turbulent effect from the Voellmy rheology. Lateral spreading is significant. A higher yield rate results in a flatter rear. For channellised flows (series B), longitudinal stretching is dominant but lateral spreading is trivial because of side confinement, as shown in Fig. 7(b). The convex front deposits in the horizontal zone while the narrow concave rear is still up in the transition zone that is partially confined. Entrainment with a higher yield rate produces a blunter, less pointed front.

The deposit profiles and thickness distributions are also included in Fig. 7, showing a blunt concave front (unconfined flow, series A) and a tongue-shaped front (channellised flow, series B) respectively. A higher yield rate always corresponds to a wider front and a longer propagation. For the same yield rate, the front of the channellised flow (series B) displaces further than that of the unconfined flow (series A). It is also noted that the maximum deposit thickness locates largely in the mid-deposit, or slightly towards the front, although the front and the tail are thinly distributed. The centre of mass of the deposit is almost around its maximum thickness. The mass profiles are cut longitudinally along the centre of the descending axis of the flow (Fig. 8), shaping from a relatively thick tail and a thin front to a thick body and a thin proximal end in the deposition zone. A higher erosion rate corresponds to a thicker deposit depth.

In comparison, in Figs 9(a1) and 9(b1), the entrainment and runout geometry strongly influence the variations of mean velocity. Generally, the entire body of the debris moves faster, but it also halts faster owing to the increase of system inertia through erosion. Under the same yield rate, the mean velocity of the channellised flow has a higher peak value but decreases faster than that of the unconfined flow. The volumetric variation with time is presented in Figs 9(a2) and 9(b2). Again, for the same yield rates, the unconfined flows remove more material from the bed during runout than the channellised ones. The front velocity during runout is depicted in Figs 9(a3) and 9(b3). Its variation shows a similar trend regardless of yield rate or runout geometry conditions. Under the same runout geometry, a larger value of front velocity corresponds to a higher yield rate. Under the same yield rate, the fronts of unconfined flows move slower than those of channellised ones when they travel the same distance.

\section{Discussions on debris runout behaviour due to erosion}

Friction rheology and Voellmy rheology have been widely used to characterise granular flows/avalanches. It is interesting to note that, using friction rheology (Figs 4-6), the existence of basal erosion only marginally affects the variation pattern of mean velocity for both unconfined and channellised flows. The centres of mass of all the six cases are at nearly the same location. This suggests that the longitudinal deformation and global mobility of a slide do not substantially change under frictional rheology, although a large amount of erosive material might be added into the moving system. This observation fully agrees with the case analysis by Hungr \& Evans (1997), who postulated that the 

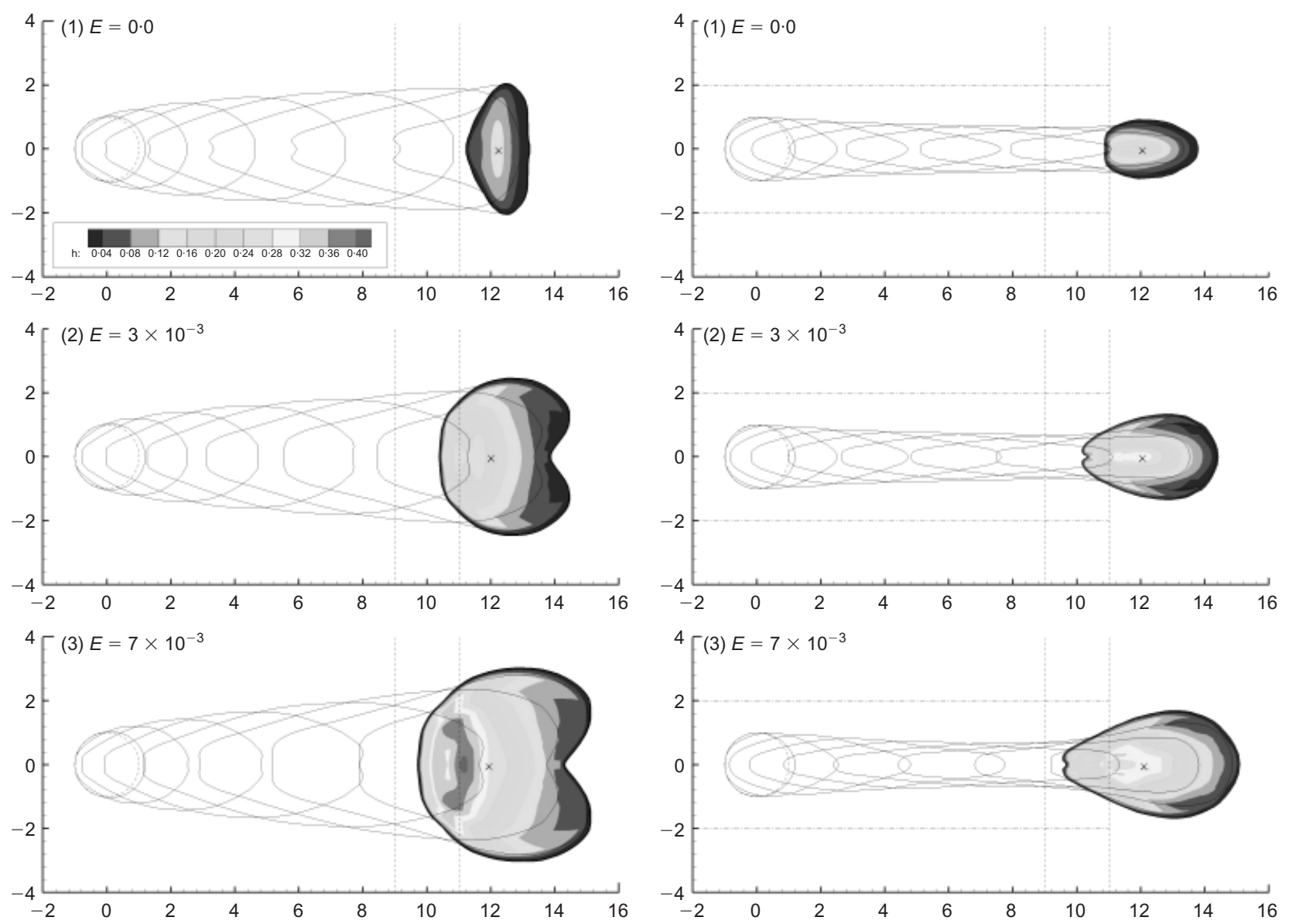

(a)

Fig. 4. Projection of debris profiles on horizontal plane (friction model): (a) unconfined flows; (b) partially confined flows. Dotted circle indicates initial shape. Flood contours show depth distribution of final deposition, with centre of mass marked $\times$. Time instants from 1 to 19 with increment 2

centrifugal force might have compensated for the initial potential energy relative to the material entrained. Our conjecture, however, is different, thanks to the curvatureless topographic setting in the major descending direction. Knowing that the influence of mass change on the moving system is directly through the net intercolumn force $\mathbf{P}$, we monitored the variation of all the acting forces during the entire runout. It turned out that the magnitudes of $\mathbf{T}$ on the inclined slope and $\mathbf{G}$ in the moving direction are roughly two orders larger than that of $\mathbf{P}$. Deformation along the downslope direction is much more dominant than lateral spreading. Consequently, the global mobility along the inclined slope cannot be significantly affected by entrainment when the $\mathbf{P}$ term is technically negligible. In the horizontal zone, where $\mathbf{G}$ has no contribution, $\mathbf{P}$ adjusts the material depth locally and much more slowly to reach an equilibrant earth pressure. Although $\mathbf{P}$ is of nearly the same order as $\mathbf{T}$, no appreciable entrainment will occur during the deposition stage. Nevertheless, it should be noted that the above observation is not applicable to Voellmy rheology, in which the increase of material depth through entrainment can significantly reduce T. Therefore the mobility will increase and push the centre of mass even further.

In the numerical experiments, the front of the channellised flows (series B) propagates further than that of the unconfined flows (series A) when comparisons are made for the same rheology and the same erosion rate (Figs 4 and 7). This agrees with the general observations that the channelling effect may enhance the runout distance, because confinement strongly influences the overall displacement and the thickness distribution in the deposition zone. In practice, for debris hazard mitigation, some techniques such as training dykes and lined channels may be deployed to confine and divert the flows, encouraging debris to continue flowing in a controlled manner through and beyond a developed area. Moreover, the volumetric accumulation processes from Figs 6(a2) and 6(b2), and Figs 9(a2) and 9(b2), demonstrate that unconfined flows erode more materials than their channellised counterparts owing to the lateral spreading. The computational results coincide with some field observations that unconfined flows typically exhibit a wide range of entrainment and deposition volume, whereas confined flows yield moderate volumes of entrainment and small volumes of deposition (Fannin \& Wise, 2001). The calculations also suggest that basal topography is an important factor influencing the debris transportation and deposition processes.

To facilitate the preliminary estimate of the yield rate, we obtained the correction coefficient by fitting the computed $A_{\text {effect }}$ and $d_{\text {centre }}$ from the above numerical experiments (for the erosion cases) back to equation (11). Correction is apparently needed to reflect the dependence on topography and rheology. For the friction model, we found $\alpha=2 \cdot 0$ for both open and channellised flows. However, for the Voellmy model, where non-linearity is much stronger, we shall use $\alpha$ $=2.2$ for the open flows and $\alpha=2.5$ for the channellised ones. 

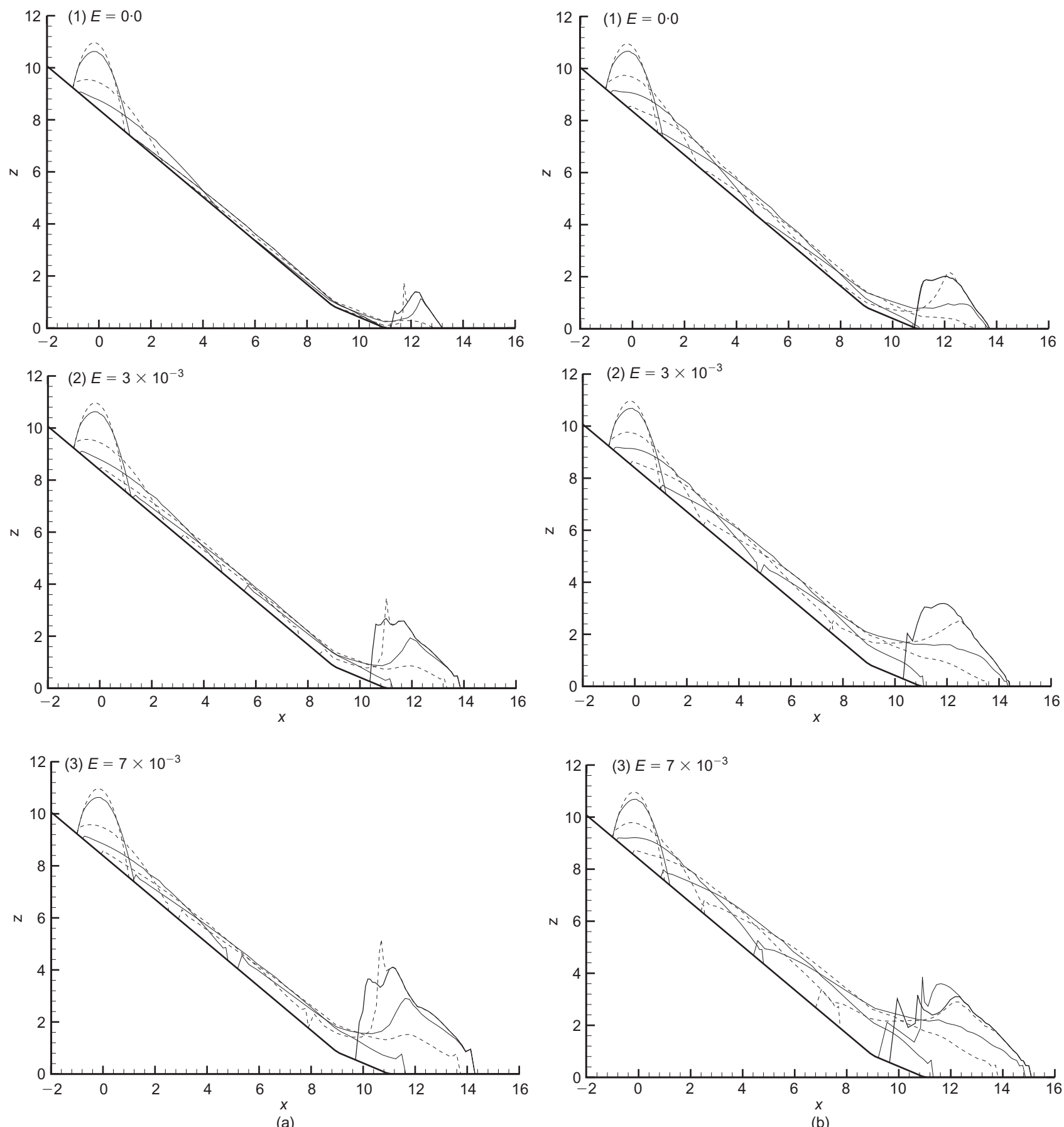

(b)

Fig. 5. Debris profiles (friction model) in vertical central plane $y=0$ at selected time steps (corresponding to Fig. 4). Debris depth exaggerated by 10

were triggered by prolonged and intense rainfall in the Valtellina area in the Central Alps, northern Italy, mostly along the northern valley flank. Terraces cover large areas along the flanks of many alpine and pre-alpine valleys. About 200 soil slips and slumps took place in the terraced slopes, and one third of them evolved into debris flows (Fig. 10). Analysis of past events (1983, 1987, 2000), aerial photos and field investigations allowed reconstruction of the pattern and characteristics of the landslides (Crosta et al., 2003). The areal distribution of the November 2000 slope failures in Valtellina is not homogeneous. An average landslide density of 11.5 failures $/ \mathrm{km}^{2}$ has been determined in terraced terrain, and the maximum value of 49.0 failures/ $\mathrm{km}^{2}$ was observed at Bianzone, the location of the selected debris flow to be studied. These landslides removed portions of cultivated areas, caused interruption of transportation corridors, and posed a hazard to the safety of people.

\section{Landslide characteristics and geotechnical properties}

Fieldwork recognised that the size at the soil-slip-debris flow source areas on terraced slopes was generally characterised by a modal value of $8 \mathrm{~m}$, but scars up to $20 \mathrm{~m}$ wide were mapped. The thickness of the Quaternary deposits at the source area ranged from 0.5 to $2.5 \mathrm{~m}$. The profile of the slip surface at the source zone varied from curvilinear or almost straight to undulating, suggesting a retrogressive distribution of activities. The averaged terrain gradient of the slopes was $42^{\circ}$. The terraced areas were retained by drystone walls, usually between 1 and $2.5 \mathrm{~m}$ in height up to 

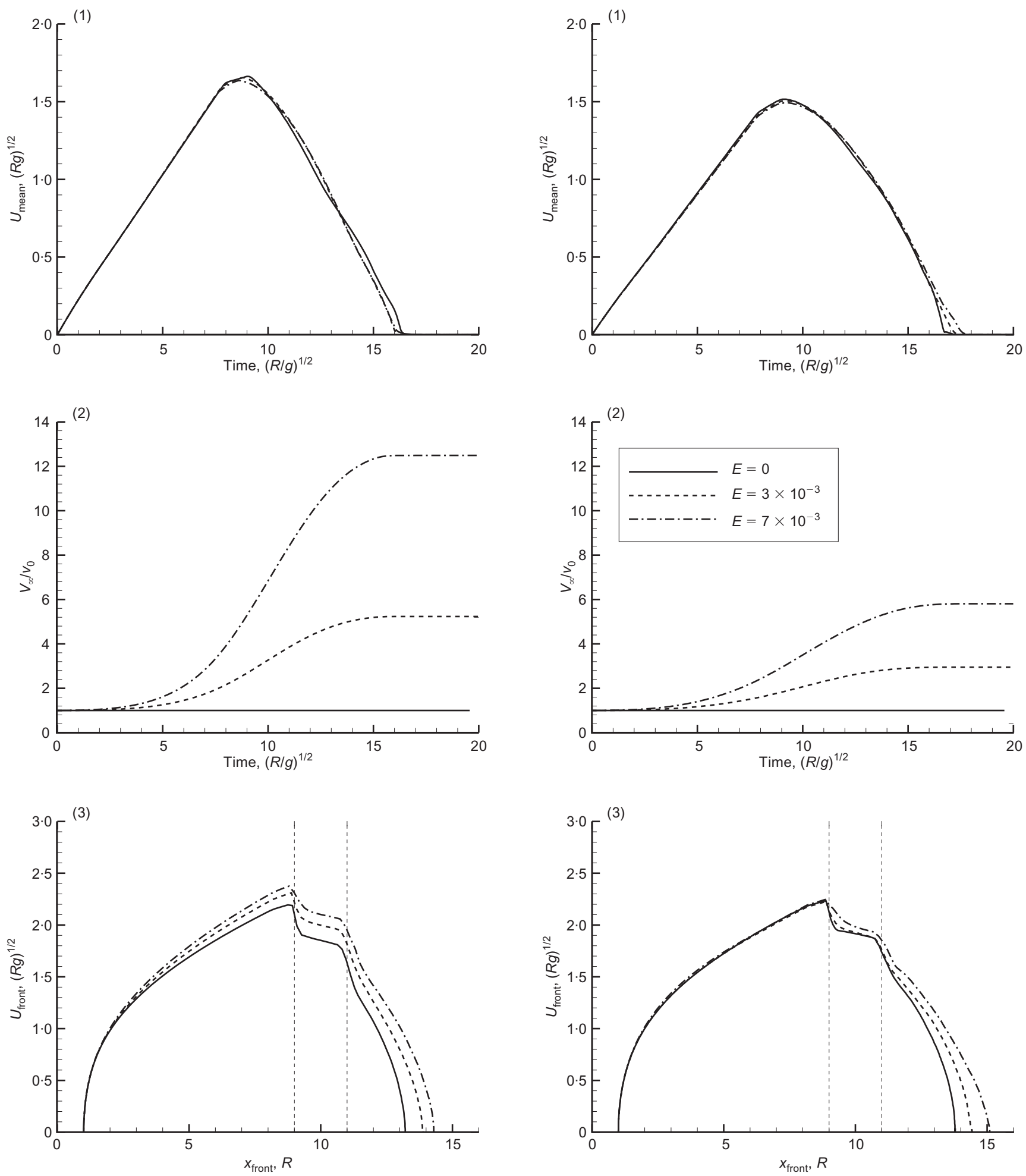

(a)

(b)

Fig. 6. Time records of some kinematic parameters (friction model): (a) unconfined; (b) partially confined

$4 \mathrm{~m}$, morphologically shaping the mean terrain gradient between $15^{\circ}$ to $25^{\circ}$. After departing from the source zone, the initial slides soon transformed into rapid, unconfined debris flows. Under the conditions of a prior prolonged period of rainfall, the loose soils on the slopes were saturated by infiltration or surficial runoff, under the control of water supply in source areas (converging slope sectors). Such weakened soils became unstable and moved downwards together with the debris flows. Debris volume was increased substantially by scouring of loose surficial deposits and scraping off vegetation. The erosion depth was usually measured usually as a few decimetres, but it reached up to $2.5 \mathrm{~m}$. A turbulent situation could have been created, especially when rapid erosion took place. Levees of unsorted materials some decimetres in height were seen. The presence of subhorizontal steps along the terraced slopes enhanced the energy loss of the debris flows. The accumulation zones usually occurred on less steep reaches as morphologic terraces or roads, where the terrain gradient was less than $10^{\circ}$. The distance travelled by the debris flows usually 

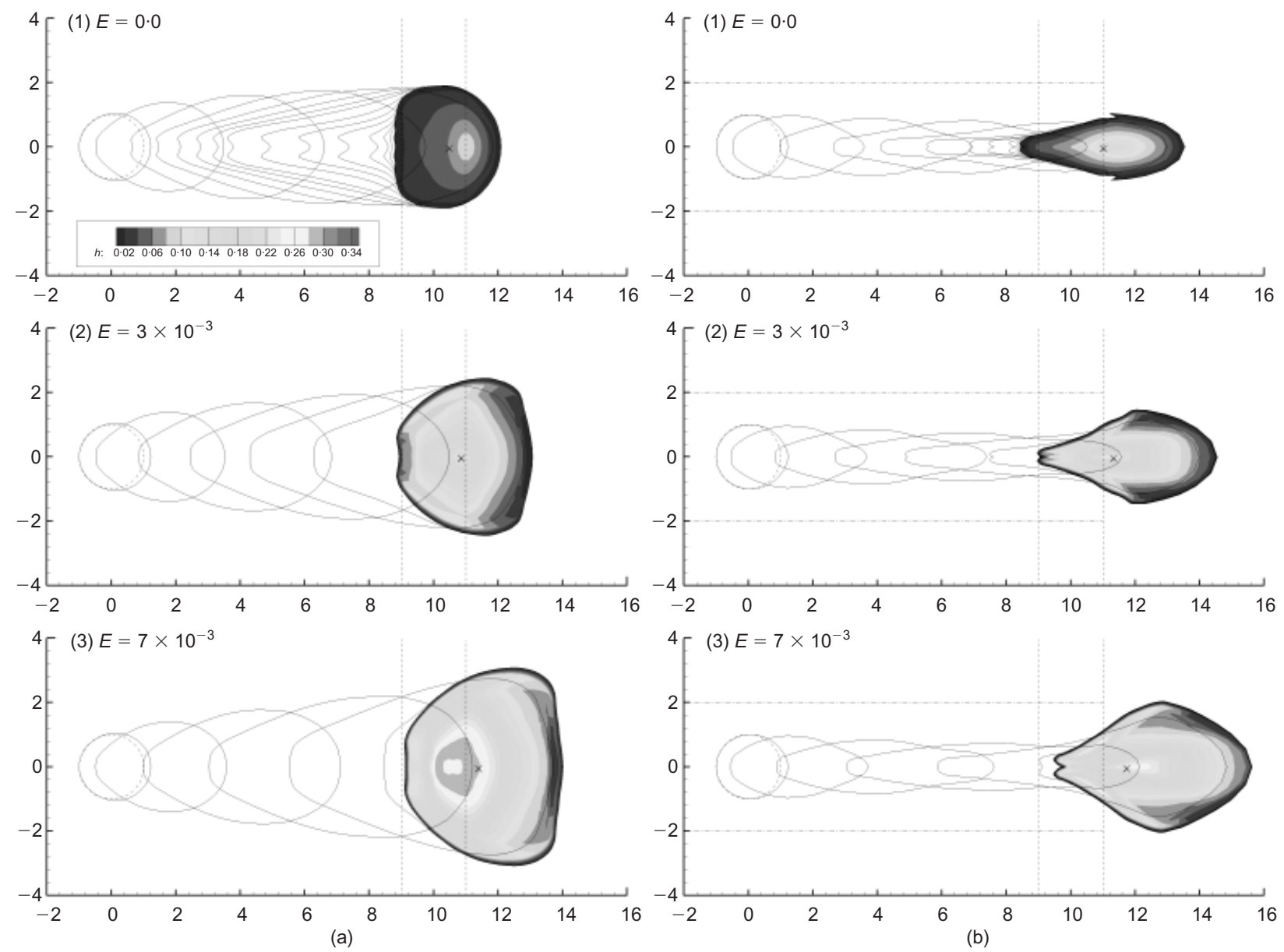

Fig. 7. Projection of debris profiles on horizontal plane (Voellmy model): (a) unconfined flows; (b) partially confined flows. Dotted circle indicates initial shape. Flood contours show depth distribution of final deposition, with centre of mass marked $\times$. Time instants from 1 to 22 with increment 3 , and from 22 to 71 or 50 with increment 7

ranged from a few metres up to $600 \mathrm{~m}$, with differences in elevations up to $230 \mathrm{~m}$. The ratio of the total fall height to the total travel length ranged from $0 \cdot 3$ to $0 \cdot 8$.

Landslips in the source area affected glacial, fluvioglacial and anthropogenically reworked deposits overlying metamorphic basement. Disturbed soil samples were collected at the landslip source zone, both above and below the slip surface. The most common type of soil was silty sand with gravel (SM). Clay content was very low, ranging from $1 \%$ to $6 \%$. The coarse soil fraction was represented by sub-angular to sub-rounded crystalline cobbles. Boulders up to $50 \mathrm{~cm}$ in diameter were observed in the coarse layers. $D_{10}$ ranged from 0.006 to $0.04 \mathrm{~mm}$, and $D_{60}$ was between 0.3 and $3.9 \mathrm{~mm}$. All the soils were poorly sorted, with a $D_{60} / D_{10}$ ratio greater than 10 . Moreover, the soils were usually not plastic and had low values of liquid limit of $16 \cdot 3-23.9 \%$, suggesting that a small amount of water could lead the soils to their viscous-fluid state. This characteristic, associated with the low clay content, facilitated the transformation of soil slips into rapid debris flows (Ellen \& Fleming, 1987; Chen et al., 2004). In addition, direct shear tests on remoulded samples exhibited a peak friction angle ranging from $34^{\circ}$ to $35^{\circ}$ without significant true cohesion.

\section{Mobility analysis}

The 200 soil-slip-debris flows in terraced slopes were similar to each other in terms of their triggering mechanism, mobilised material, geological and topographic setting, and failure mode. One of the representative cases that occurred in Bianzone, with significant erosion, is selected for mobility analysis. The schematic view of the observed erosion distribution, for illustration purposes, is marked by zones along the debris runout path (Fig. 11). Initiation of the slide occurs in zone 1, followed by entrainment along the runout path from zone 2 to zone 9, after which deposition is dominant in zones 10 and 11 with no significant entrainment. The details of the average erosion depth, area and volume are also elucidated. In the field, the eroded depth is usually higher along the centre of the runout path but lower near the two sides. It is seen that, after the release of an initial volume of $266 \mathrm{~m}^{3}$ pertinent to a footprint area of $295 \mathrm{~m}^{2}$, the mobilised debris rapidly transformed into a debris flow, entraining loose mantle soils along the downslope movement. In the deposition zone, the measured total volume of accumulation was $4084 \mathrm{~m}^{3}$, up to 16 times the initial volume.

We apply Voellmy rheology in this mobility analysis. The pre-failure topography of the landslide site is converted directly from a GIS database with a high ground resolution of $1 \times 1 \mathrm{~m}$. Associated with the source zone scar information, the discretised initial volume is $258.5 \mathrm{~m}^{3}$ with a footprint area of $295 \cdot 1 \mathrm{~m}^{2}$, very close to the field measurements. From the geotechnical properties of the mobilised material and the direct shear test results, the dynamic internal friction angle of the loose debris is taken as $\phi=$ $35^{\circ}$, the basal friction angle as $\delta=21^{\circ}$ and the bulk unit weight as $\gamma=22 \mathrm{kN} / \mathrm{m}^{3}$. We follow equation (11) to estimate the yield rate: $V_{\text {eroded }} \cong 3839 \mathrm{~m}^{3}, A_{\text {effect }} \cong 6585 \mathrm{~m}^{2}$ (both are available by summing up zones $2-9$ in Fig. 11) and $d_{\text {centre }} \cong 320 \mathrm{~m}$, which altogether yields preliminarily $E$ $\cong 4.0 \times 10^{-3}$ after correction with $\alpha=2 \cdot 2$. It turns out to 

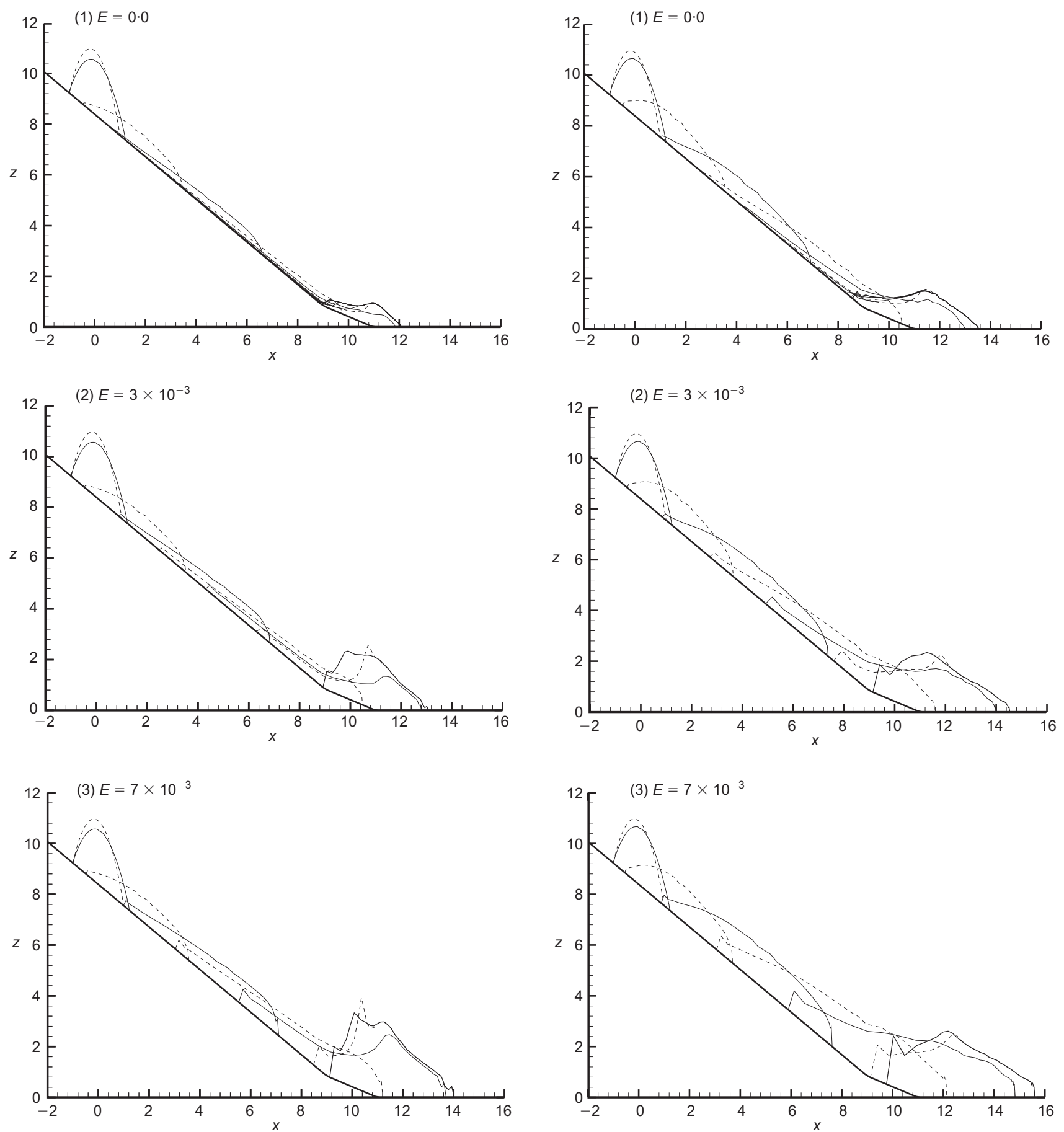

(a)

(b)

Fig. 8. Debris profiles (Voellmy model) in vertical central plane $y=0$ at selected time steps (corresponding to Fig. 7). Debris depth exaggerated by 10

be a surprisingly good guess that gives the best recovery of the measured final volume in our trials, and is therefore taken for the present analysis. Considering the fahrböschung, the pore pressure caused by rainfall infiltration and the turbulence effect, we find that $\xi=1000 \mathrm{~m} / \mathrm{s}^{2}$ produces the best correlation with the field inspections.

Figure 12(a) is a site photograph taken shortly after the subject failure. Perspective snapshots of the simulated runout process are compared in Fig. 12(b) in order to have a dynamic replay of the spatial event. The movement appears to be divided into a starting phase, a fully developed flow phase, and a deposition phase. The initial situation is described by a static condition with zero velocity of the source material. After detachment from the source area, the mobilised material moves down the slope under gravity, deforming as it goes. The fully developed flow phase features an increasing volume of additional material through surficial erosion process, an elongation of flow length along the moving direction, and an increasing velocity for the front propagation. Trivial overflows occur unevenly along the edge of flow path in the early stage of movement as the result of a relatively flat terrace just below the source area. It is also seen that the predominant direction of movement adapts with the topography. Controlled essentially by the front velocity, the debris travels along the major descending axis of the slope and spreads on the less steep reaches. Around the 

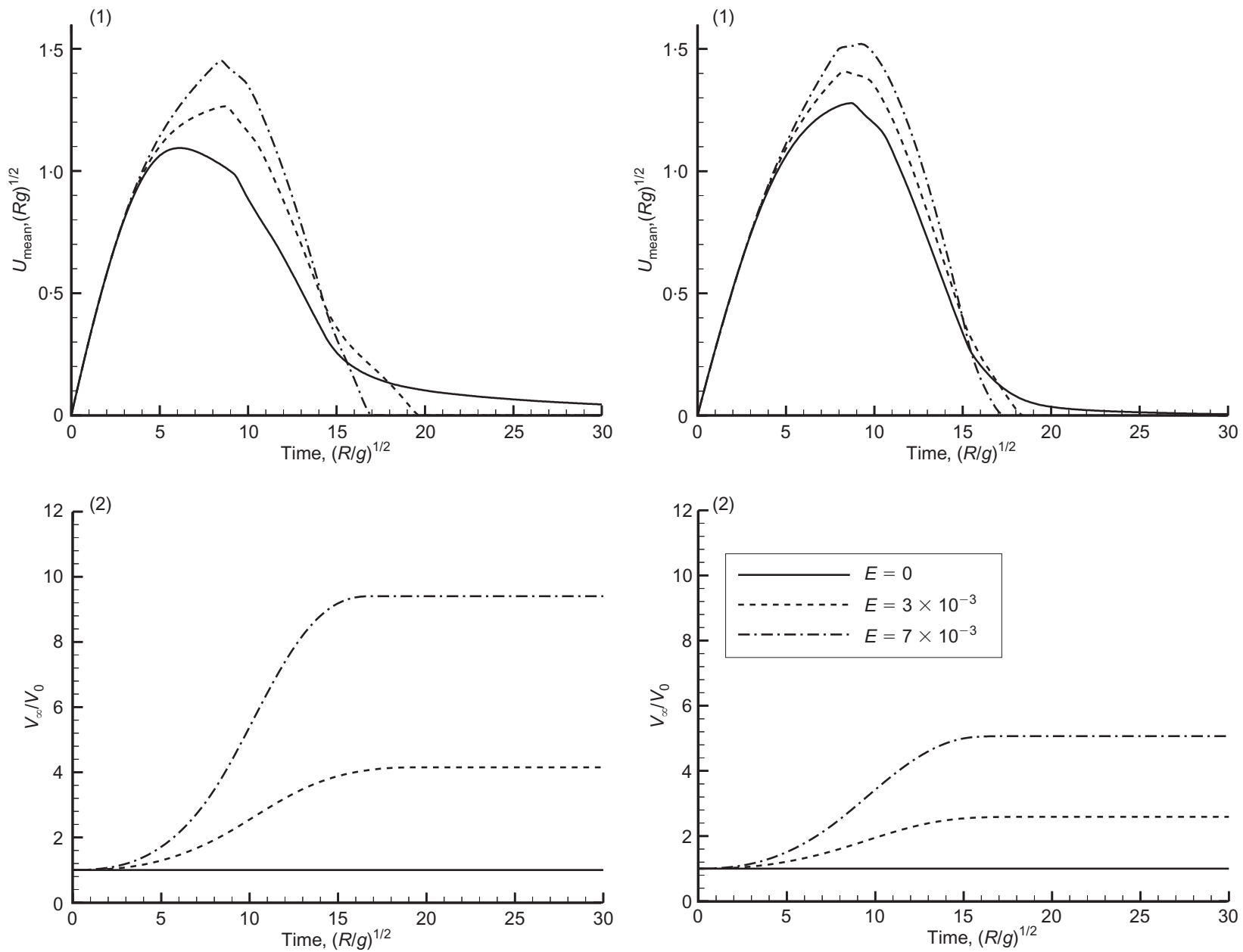

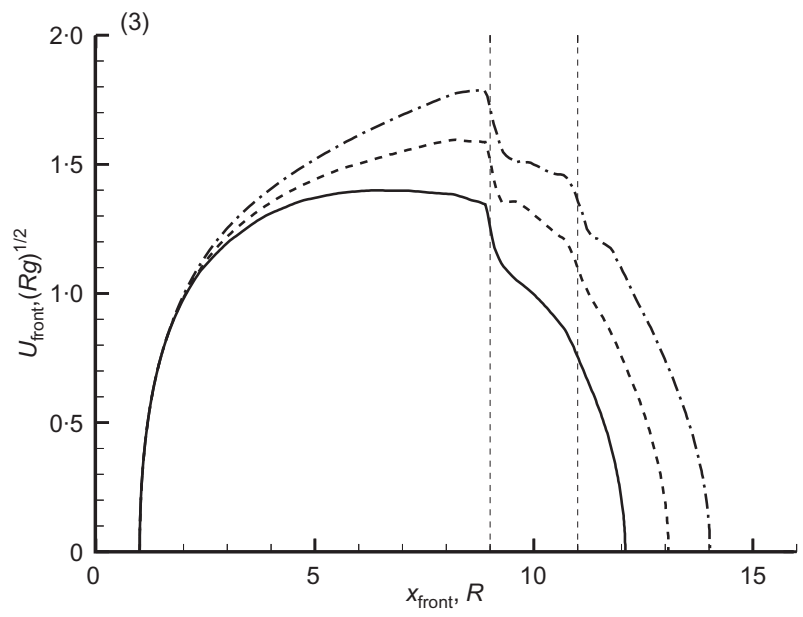

(a)

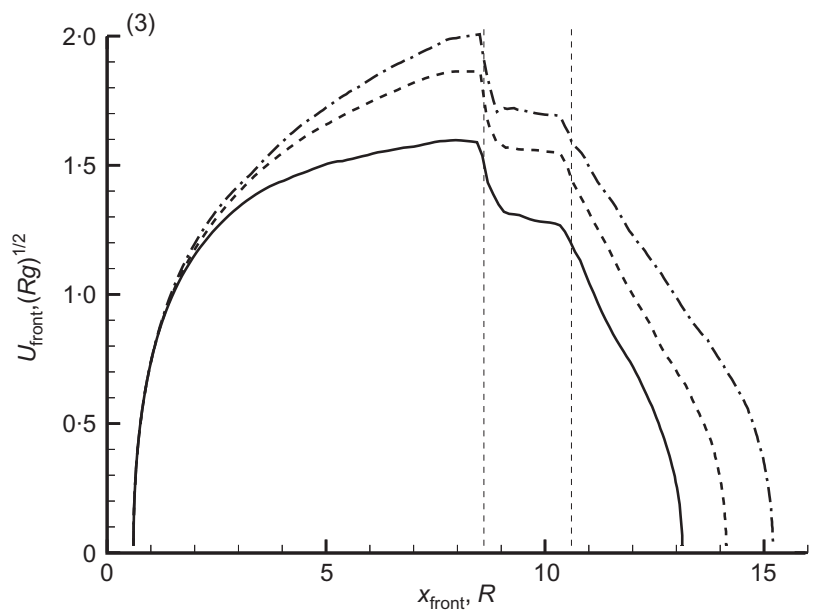

(b)

Fig. 9. Time records of some kinematic parameters (Voellmy model): (a) unconfined; (b) partially confined

distal parts of the apron, deposition dominates with scarcely any erosion, featuring a blunt front and a less wide rear. The proximal part pushes forward slowly while the front progressively approaches ahead with lateral adjustment. The simulated deposit scar in the deposition zone matches the observed scar reasonably well. The simulated runout visually provides an excellent match to the field measurements on the general shapes of runout path and deposit scar. The deposition forms ridges perpendicular to the major sliding direction with a maximum thickness of about $4.8 \mathrm{~m}$.

The time history of some pertinent parameters (mean velocity and footprint area) is shown in Fig. 13(a). When the debris front arrives at the foot of the slope, with mainly elongation and slight spreading out, the volume-averaged velocity reaches a maximum of $12.1 \mathrm{~m} / \mathrm{s}$ at $t=22.6 \mathrm{~s}$ while the front travels as fast as $20.0 \mathrm{~m} / \mathrm{s}$. This specific moment corresponds to the maximum kinetic energy and momentum released from the moving debris. During this period, the footprint area also increases continuously and steadily. With concomitant forward movement at $t=27.6 \mathrm{~s}$ as the front runs on the downslope fan, the movement decelerates. The largest footprint area of $5158 \mathrm{~m}^{2}$ is reached, which is about 17 times the initial footprint in the source zone. Following the onset of deposition, the velocity decays rapidly. Mean- 


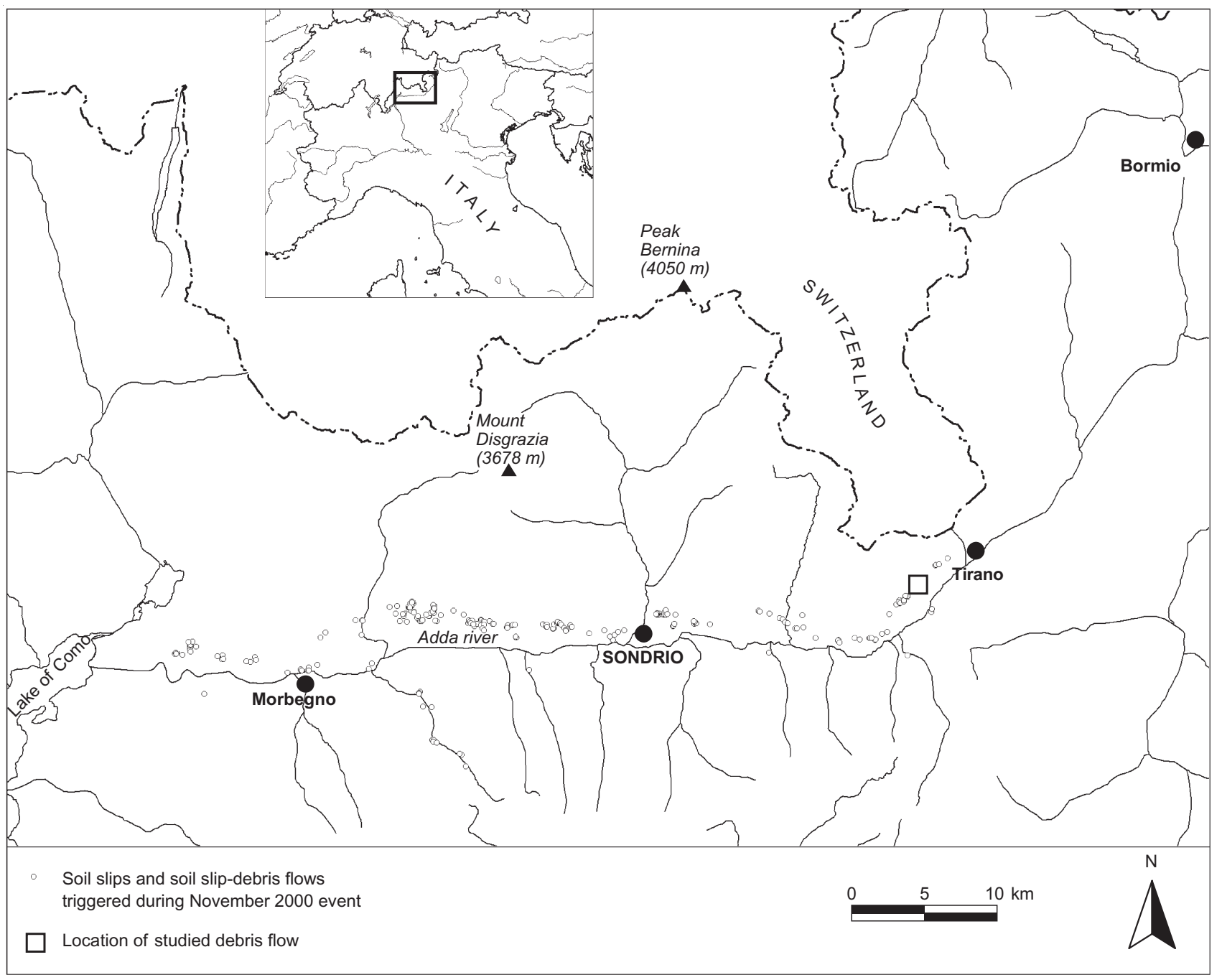

Fig. 10. Map of Valtellina area showing location of debris flow to be analysed

while, the footprint area reduces, accompanied by forward pushing by the debris rear and rapid deceleration of the front. The debris is stabilised at $t=36 \mathrm{~s}$ with a footprint area of $2866 \mathrm{~m}^{2}$.

Volumetric variations along the path of movement are shown in Fig. 13(b). For the subject event, the initial failure volume is followed by entrainment of surficial material along the runout path. The cumulative flow volume has thus been increasing before deposition occurs. The variation of the gradient of the cumulative flow volume records the net volume change during runout. As indicated in our proposed mechanism, the volume of entrained material is proportional to the contact surface area and the debris moving velocity. From Fig. 13(a), the peak of the net volume change occurs neither at the instant of maximum mean velocity nor at the largest footprint area. This is because soil loss is unlikely to vary directly with increasing slope angle (Warburton et al., 2003). For the present event, the maximum net volume change, about $240 \mathrm{~m}^{3} / \mathrm{s}$, occurs around $t=24.7 \mathrm{~s}$. After this instant the net volume change declines, although the cumulative flow volume still develops. The final debris volume in the deposition fan is $4142 \mathrm{~m}^{3}$, which is close to the field inspection by less than $1.5 \%$.

In order to compare with the available data from field measurements (Fig. 11), we computed, according to equation (9), the entrainment depth by integrating $E|\mathbf{u}|$ over the entire runout time and the erosion-affected footprint area. The temporal and spatial accumulation of erosion depth on the affected surface is presented in Fig. 14. Generally, entrain- ment is seen to be more prevalent on the steeper reaches than on the deposition gentle reaches, which is consistent with some field observations (e.g. Fannin \& Wise, 2001). The overall resemblance between the present computation and the field data is convincing. Our result shows that more than $31 \%\left(1216 \mathrm{~m}^{3} / 3883 \mathrm{~m}^{3}\right)$ of the eroded material comes from zones $6-8$, and the field measurement is approximately $33 \%\left(1292 \mathrm{~m}^{3} / 3839 \mathrm{~m}^{3}\right)$. In particular, the maximum erosion depth of $0.92 \mathrm{~m}$ occurs in zone 7 at the hill foot, which correlates well with the observed value of about $0.8 \mathrm{~m}$ (averaged) exactly in the same narrow zone. The above integration of entrainment depth is also useful in carrying out simulations for hazard assessments where thickness of soil cover (maximum erodible depth) is available or can be inferred as a typical bedrock condition. It can be implemented numerically by turning off the erosion module locally where the accumulated erosion height exceeds a prescribed threshold value.

\section{CLOSING REMARKS}

Basal erosion is the interaction between the moving material and basal topsoil during shearing along their contact surface. This dynamic action occurs between two systems: the original moving material and the additional material through basal erosion. The magnitude of a debris flow event is thus determined more by the volume of the material entrained along the runout path than by the initial volume. In post-event investigations, gullies usually have a relatively 


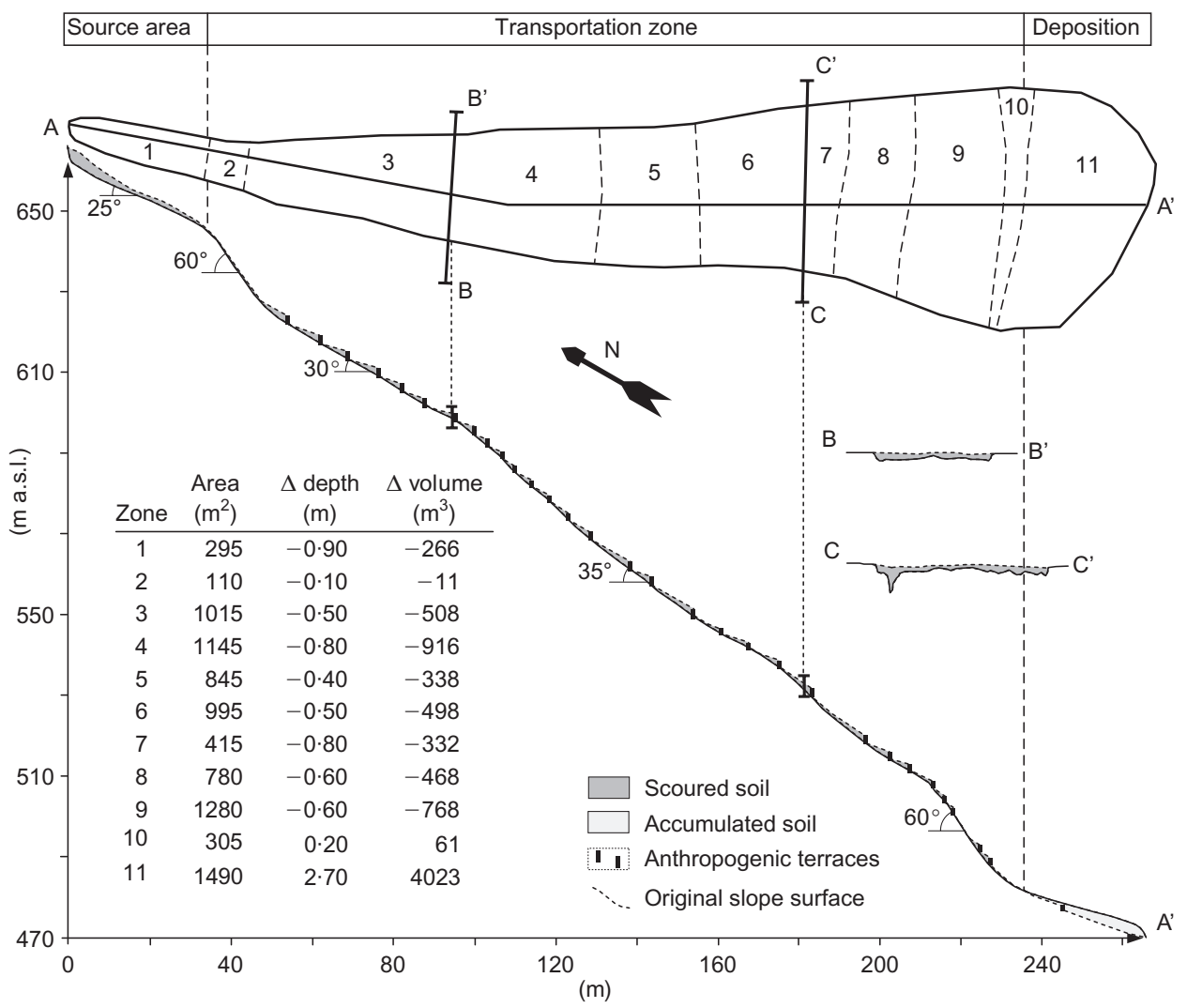

Fig. 11. Schematic views of plan and central longitudinal section from source area to deposition (thickness of soil cover is magnified by 2). Field estimation of erosion distribution along runout path tabulated in terms of zones
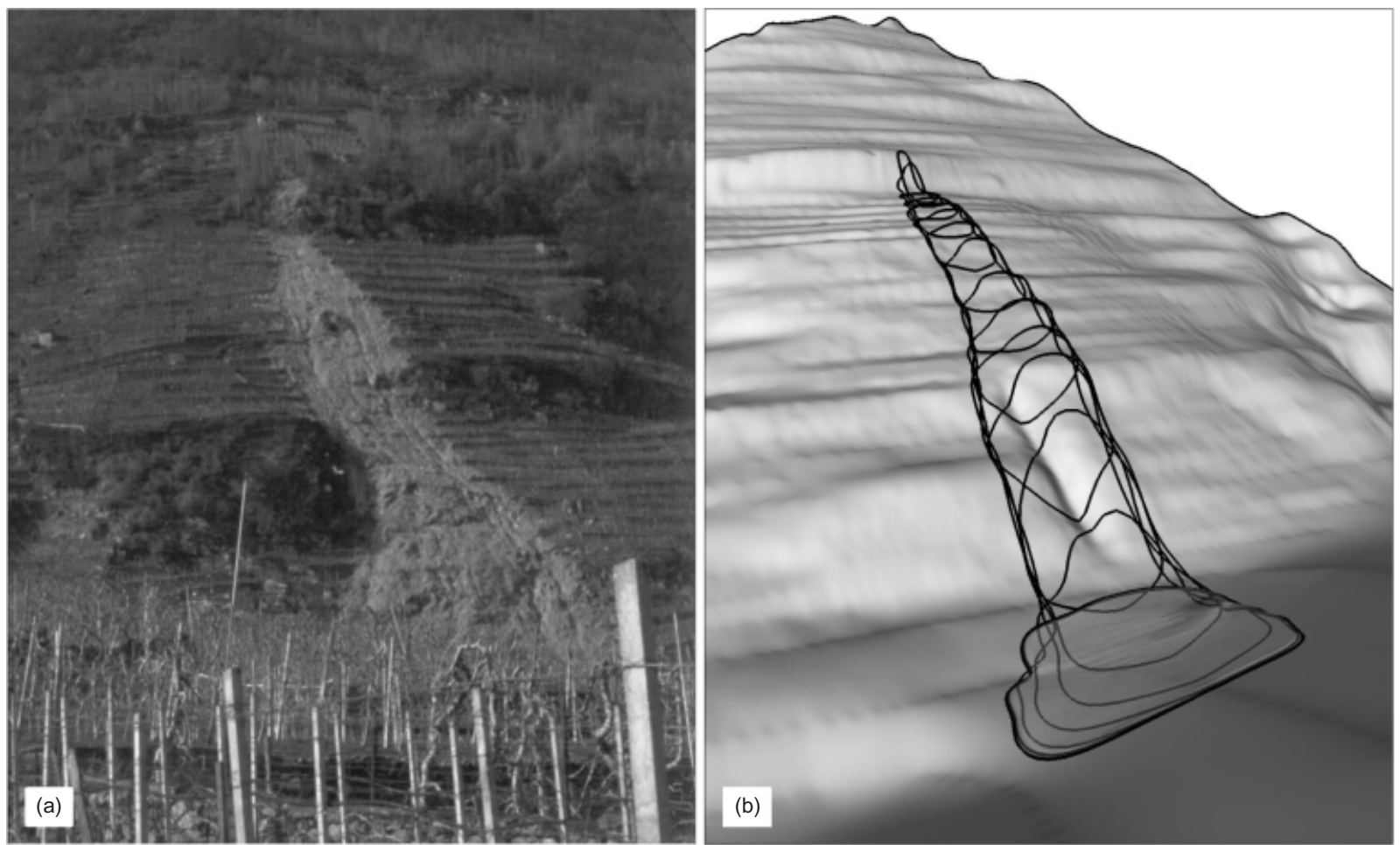

Fig. 12. Perspective views of slope failure: (a) picture of site taken shortly after the event; (b) computed debris margins at selected moments (frame interval $=2.5 \mathrm{~s}$ ). Flood contours show distribution of deposition depth

small surface area of erosion, although they are deeply incised and commonly associated with long runout, whereas open slopes generally have a relatively large area of erosion but with shallow surface lowering. Although the evaluation of surface lowering is crucial in the erosion/entrainment process, field measurements of the likely erosion depth of a debris flow are very difficult to determine, especially for gullies with loose bed and banks. Instead, the surface area 


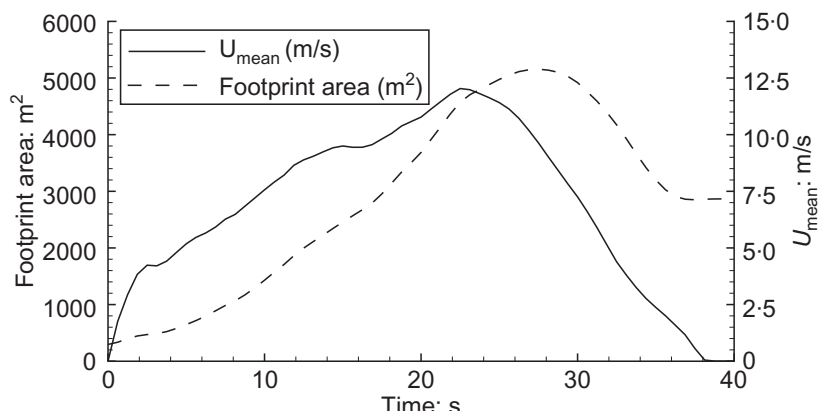

(a)

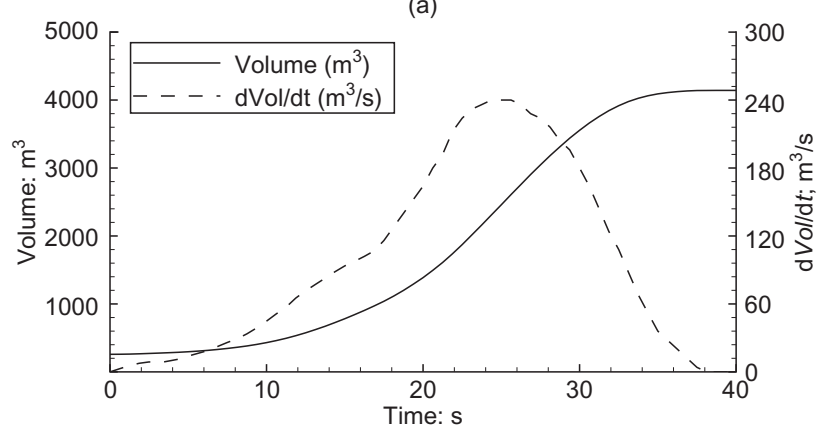

(b)

Fig. 13. (a) Time records for overall kinematic parameters; (b) volumetric variation along path of movement

likely to be affected by erosion and the volume of erodible materials can be evaluated. Therefore erosion evaluation is more meaningful and practical if measured in volume and area to be affected by erosion, which leads easily to the estimation of erosion rate. Two areas affected by erosion could have the same values of area but might produce debris accumulation at very different erosion rates. For practical engineering purposes, and especially for the back-analysis of field case histories, we propose a new concept of yield rate based on the assumption that the volume eroded is proportional to the surface area to be affected and the material moving velocity. Defined in a dimensionless form, the yield rate can be rationally and conveniently estimated in the field or measured in physical models.

Based on the mechanisms of basal erosion, we established the mathematical model and numerical implementation associated with various constitutive rheologies. Furthermore, we set up numerical experiments to evaluate parametrically the erosional effects on debris runout behaviours and global mobility, considering such factors as basal topography, rheologic closure and yield rate. The simulated results are consistent with experimental and field observations. Moreover, the proposed method has been applied to analyse a recent debris flow event occurred in Valtellina area in Central Alps, northern Italy. The selected rheologic relationship and parameters produced an excellent simulation in comparison with the available field data. The proposed concept of yield rate and the dynamic model give a plausible potential application to the analyses of landslide/debris flows with significant erosion.

\section{APPENDIX 1. EQUIVALENCE BETWEEN}

RECTANGULAR AND CURVILINEAR COORDINATES

As for other mechanical problems, the mobility analysis of debris flows has to be settled in a predefined frame of reference and coordinate system. The combinations consist of

(a) curvilinear coordinates in a Eulerian frame (e.g. Denlinger \& Iverson, 2001)

(b) curvilinear coordinates in a Lagrangian frame (e.g. Koch et al., 1994)

(c) rectangular coordinates in a Eulerian frame (e.g. Denlinger \& Iverson, 2004)

(d) rectangular coordinates in a Lagrangian frame (e.g. Chen \& Lee, 2000).

Derived from the bulk force analysis on debris columns in fixed rectangle coordinates, the present formulation is, however, equivalent to that based on the normal-depth integration in the bed-fitted curvilinear coordinates.

Consider dry granular material $\left(\xi^{\prime} \rightarrow \infty\right)$ sliding uniformly downward along a two-dimensional non-erosional slope in the $x-z$ plane $\left(w_{\mathrm{f}}=w_{\mathrm{b}}=0\right)$ : equations (29) and (13) reduce (in the point differential form) to

$$
\begin{aligned}
& \frac{\mathrm{d} u}{\mathrm{~d} t}=-\frac{g^{\prime}}{q^{2}} \frac{\partial b}{\partial x}-\frac{u}{|\mathbf{u}|} \frac{g^{\prime}}{q} \tan \delta \\
& w=u \frac{\partial b}{\partial x}
\end{aligned}
$$

Let $\theta(x)$ be the local angle between the tangential plane and the horizontal plane at location $x(t)$ : we have $\partial b / \partial x \equiv-\tan \theta$. Equations (31) and (32) thus become

$$
\begin{aligned}
\frac{\mathrm{d} u}{\mathrm{~d} t} & =g^{\prime} \frac{\tan \theta}{1+\tan ^{2} \theta}-\frac{u}{|\mathbf{u}|} \frac{1}{\left(1+\tan ^{2} \theta\right)^{1 / 2}} g^{\prime} \tan \delta \\
& =g^{\prime}\left(\cos \theta \sin \theta-\cos ^{2} \theta \tan \delta\right) \\
w & =-u \tan \theta
\end{aligned}
$$

From equation (16), we have

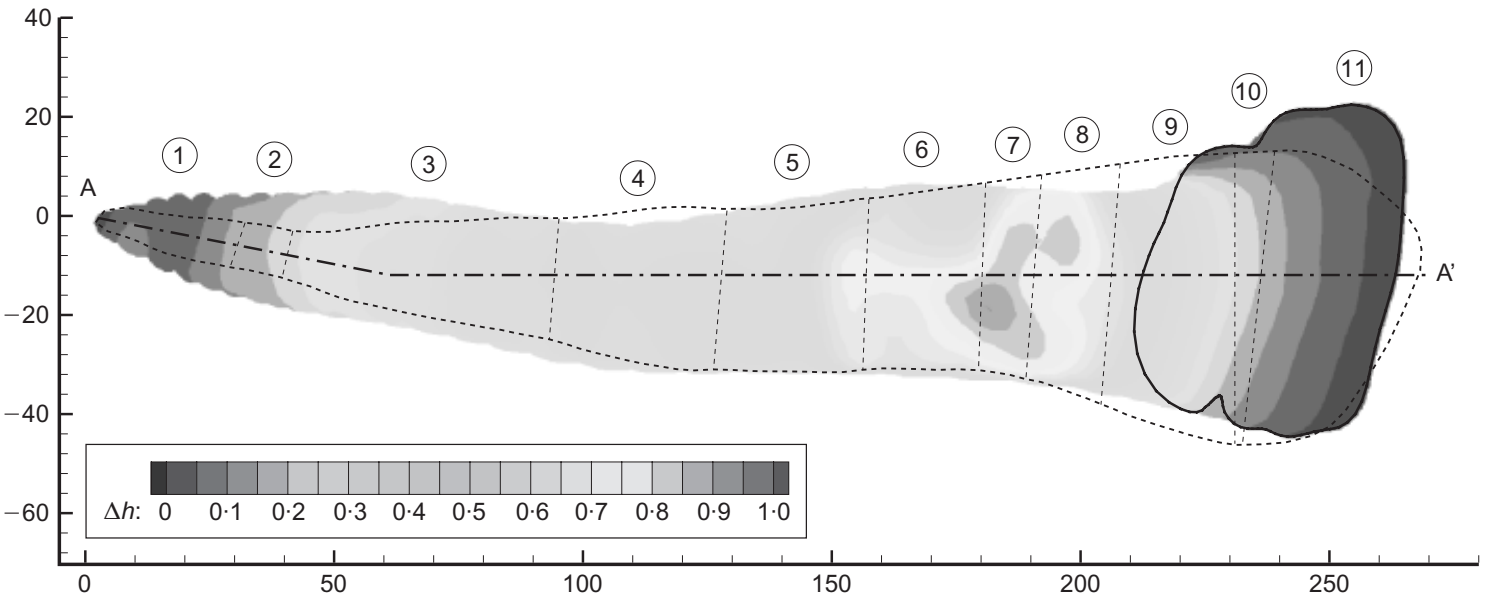

Fig. 14. Distribution contours of overall eroded debris depth after runout 


$$
\begin{aligned}
\Delta g & =\frac{\mathrm{d} w}{\mathrm{~d} t}-\frac{\mathrm{d} u}{\mathrm{~d} t} \frac{\partial b}{\partial x}=\frac{1}{\mathrm{~d} t}(-u \tan \theta)+\frac{\mathrm{d} u}{\mathrm{~d} t} \tan \theta \\
& =-u \frac{\mathrm{d}}{\mathrm{d} t} \tan \theta=-u \sec ^{2} \theta \frac{\mathrm{d} \theta}{\mathrm{d} t}
\end{aligned}
$$

Note that the following relationships hold:

$$
\begin{aligned}
& u=u_{s} \cos \theta \\
& \frac{\mathrm{d} \theta}{\mathrm{d} t}=-\frac{u_{\mathrm{s}}}{R}=-u_{\mathrm{s}} \kappa
\end{aligned}
$$

where $u_{\mathrm{s}}$ is the tangential velocity and $\kappa=1 / R$ is the local curvature of the slope at $x(t)$. The minus sign in equation (37) is taken due to the definition of $\theta$. Substituting equations (36) and (37) into equation (35), we hence have

$$
g^{\prime}=g+\Delta g=g+\frac{u_{\mathrm{s}} \cos \theta}{\cos ^{2} \theta} u_{\mathrm{s}} \kappa=g+u_{\mathrm{s}}^{2} \kappa \sec \theta
$$

Using equations (36) and (37) again and with equation (38), the lefthand side of equation (33) appears as

$$
\begin{aligned}
\operatorname{LHS}(33) & =\frac{\mathrm{d}}{\mathrm{d} t}\left(u_{\mathrm{s}} \cos \theta\right)=\frac{\mathrm{d} u_{s}}{\mathrm{~d} t} \cos \theta-u_{\mathrm{s}} \sin \theta \frac{\mathrm{d} \theta}{\mathrm{d} t} \\
& =\frac{\mathrm{d} u_{s}}{\mathrm{~d} t} \cos \theta+u_{\mathrm{s}}^{2} \kappa \sin \theta
\end{aligned}
$$

and its right-hand side is equivalent to

$$
\begin{aligned}
\operatorname{RHS}(33) & =\left(g+u_{\mathrm{s}}^{2} \kappa \sec \theta\right)\left(\cos \theta \sin \theta-\cos ^{2} \theta \tan \delta\right) \\
& =u_{\mathrm{s}}^{2} \kappa \sin \theta+\left[g \sin \theta-\left(g \cos \theta+u_{\mathrm{s}}^{2} \kappa\right) \tan \delta\right] \cos \theta(40)
\end{aligned}
$$

Equating equations (39) and (40) and cancelling the common terms, we arrive at

$$
\frac{\mathrm{d} u_{\mathrm{s}}}{\mathrm{d} t}=g \sin \theta-\left(g \cos \theta+u_{\mathrm{s}}^{2} \kappa\right) \tan \delta
$$

which is exactly the form presented in the curvilinear coordinate system.

With the help of equation (13), $\Delta g$ can be computed conveniently via equation (16) using the Euler forward finite difference, say, as follows:

$$
\begin{aligned}
\Delta g^{n+1}= & \frac{w^{n+1}-w^{n}}{\Delta t}-\frac{u^{n+1}-u^{n}}{\Delta t}\left(\frac{\partial b}{\partial x}\right)^{n+1} \\
& -\frac{v^{n+1}-v^{n}}{\Delta t}\left(\frac{\partial b}{\partial y}\right)^{n+1} \\
= & \frac{1}{\Delta t}\left[w^{n+1}-u^{n+1}\left(\frac{\partial b}{\partial x}\right)^{n+1}-v^{n+1}\left(\frac{\partial b}{\partial y}\right)^{n+1}\right. \\
& \left.+u^{n}\left(\frac{\partial b}{\partial x}\right)^{n+1}+v^{n}\left(\frac{\partial b}{\partial y}\right)^{n+1}-w^{n}\right] \\
= & \frac{1}{\Delta t}\left[\frac{1}{2}\left(w_{\mathrm{b}}^{n+1}+w_{\mathrm{f}}^{n+1}\right)+u^{n}\left(\frac{\partial b}{\partial x}\right)^{n+1}\right. \\
& \left.+v^{n}\left(\frac{\partial b}{\partial y}\right)^{n+1}+w^{n}(-1)\right]
\end{aligned}
$$

The last three terms, essentially $\mathbf{u}^{n} \cdot \nabla b^{n+1}$ or $-\mathbf{u}^{n+1} \cdot \nabla b^{n}$, suggest that the centripetal effect can be evaluated in the Lagrangian moving reference by conceptually 'feeling' the local topography with the lagged (or advanced) velocity, without direct computation of the bed curvature. Through Taylor series, it may easily be shown that the leading term in $\mathbf{u}^{\mathrm{n}} \cdot \nabla b^{n+1}$ is $\Delta t(\mathbf{u} \cdot \mathbf{u}) \nabla^{2} b$ at time level $n$, where $\nabla^{2} b$ is intermediately related to the mean curvature of the slope $\kappa=\nabla \cdot \mathbf{n}$.

\section{ACKNOWLEDGEMENTS}

The authors thank Dr Paolo Frattini and Dr Nicoletta Fusi for assistance in preparing the field data on the Bianzone debris flows. The second author is partially funded by the LESSLOSS EC project and the FIRB RBAU014LRS project.
The insightful critiques of the manuscript by two anonymous reviewers are greatly appreciated.

\section{NOTATION}

The following symbols are used in this paper:

$A_{c}$ material column contact area on basal surface

$A_{\text {effect }}$ total erosion-affected area

$b$ basal elevation

$d_{\text {center }}$ travel distance of center of mass

$E$ erosion rate

$f$ free-surface elevation

F volumetric force density

G gravity force

$h$ debris depth

k anisotropic earth pressure coefficients

$k^{\text {act/pas }}$ lateral earth pressure coefficients in active/passive state

$L$ reference length

$\mathbf{N}$ basal normal force

$\mathbf{P}$ net inter-column force

$q$ inclination between the tangent plane of bed and horizontal plane

$Q$ mass flux rate

$r_{u}$ pore pressure ratio

$S$ bounding surface of a debris column

T shear traction force

u velocity vector $(u, v, w)^{\mathrm{T}}$

$V_{\text {eroded }}$ total eroded volume

$\mathbf{x}$ rectangular coordinates in Lagrangian frame

$\alpha$ correction coefficient for estimating yield rate

$\gamma$ unit weight

$\delta$ dynamic basal friction angle

$\zeta$ turbulent coefficient in Voellmy rheology

$\boldsymbol{\eta}$ local transversal direction of movement in horizontal plane

$\mu$ ratio between basal shear force and basal normal force

$\xi$ local direction of movement in horizontal plane

$\rho$ bulk density

$\rho_{b} \quad$ bulk density of basal material

$\phi$ internal friction angle

\section{REFERENCES}

Cannon, S. H. (1989). An evaluation of the travel distance potential of debris flows, Miscellaneous Publication 89-2. Salt Lake City: Utah Geological and Mineral Survey.

Cannon, S. H. \& Savage, W. Z. (1988). A mass change model for the estimation of debris flow runout. J. Geol. 96, 221-227.

Chen, H. \& Lee, C. F. (2000). Numerical simulation of debris flows. Can. Geotech. J. 37, No. 1, 146-160.

Chen, H. \& Lee, C. F. (2002). Runout analysis of slurry flows with Bingham model. ASCE J. Geotech. Geoenviron. Engng 128, No. 12, 1032-1042.

Chen, H. \& Lee, C. F. (2003). A dynamic model for rainfallinduced landslides on natural slopes. Geomorphology 51, No. 4, 269-288.

Chen, H., Lee, C. F. \& Law, K. T. (2004). Causative mechanisms of rainfall-induced fill-slope failures. ASCE J. Geotech. Geoenviron. Engng 130, No. 6, 593-602.

Corominas, J. (1995). Evidence of basal erosion and shearing as mechanisms contributing the development of lateral ridges in mudslides, flow-slides, and other flow-like gravitational movements. Engng Geol. 39, Nos 1-2, 45-70.

Crosta, G. B., Dal Negro, P. \& Frattini, P. (2003). Soil slips and debris flows on terraced slopes. Nat. Hazards Earth Syst. Sci. 3, $31-42$.

Crosta, G. B., Chen, H. \& Lee, C. F. (2004). Replay of the 1987 Val Pola Landslide, Italian Alps. Geomorphology 60, Nos 1-2, $127-146$.

Crosta, G., Imposimato, S. \& Roddeman, D. (2006). Continuum numerical modelling of flow-like landslides. In Landslides from Massive Rock Slope Failure (eds S. G. Evans, G. S. Mugnozza, A. Strom and R. L. Hermanns). Heidelberg: Springer.

Denlinger, R. P. \& Iverson, R. M. (2001). Flow of variably fluidized granular masses across three-dimensional terrain: 2. Numerical 
predictions and experimental tests. J. Geophys. Res. 106, No. B1, 553-566.

Denlinger, R. P. \& Iverson, R. M. (2004). Granular avalanches across irregular three-dimensional terrain: 1 . Theory and computation. J. Geophys. Res. 109, F01014.

Ellen, S. D. \& Fleming, R. W. (1987). Mobilizations of debris flows from soil slips, San Francisco Bay region, California. Rev. Engng Geol. 7, 31-40.

Erlichson, H. (1991). A mass-change model for the estimation of debris-flow runout, a second discussion: Conditions for the application of the rocket equation. J. Geol. 99, 633-634.

Fannin, R. J. \& Rollerson, T. P. (1993). Debris flows: some physical characteristics and behaviour. Can. Geotech. J. 30, No. 1, $71-81$.

Fannin, R. J. \& Wise, M. P. (2001). An empirical-statistical model for debris flow travel distance. Can. Geotech. J. 38, No. 5, 982-994.

Foster, G. R. \& Meyer, L. D. (1972). A closed-form erosion equation for upland areas. In Sedimentation: Symposium to Honor Prof. H. A. Einstein (ed. H. W. Shen), pp. 12/1-12-19. Fort Collins, CO: Colorado State University.

Gabriels, D. (1999). The effect of slope length on the amount and size distribution of eroded silt loam soils: short slope laboratory experiments on interhill erosion. Geomorphology 28, Nos 1-2, $169-172$.

Govindaraju, R. (1998). Effective erosion parameters for slopes with spatially varying properties. J. Hydraul. Engng, ASCE 124, No. 2, 81-88.

Gray, J. M. N. T., Wieland, M. \& Hutter, K. (1999). Gravity-driven free surface flow of granular avalanches over complex basal topography. Proc. R. Soc. London, Ser. A 455, 1841-1874.

Hungr, O. (1990a). A mass-change model for the estimation of debris-flow runout: a discussion. J. Geol. 98, 791.

Hungr, O. (1990b). Momentum transfer and friction in the debris of rock avalanche: discussion. Can. Geotech. J. 27, 697.

Hungr, O. (1995). A model for the runout analysis of rapid flow slides, debris flows, and avalanches. Can. Geotech. J. 32, 610-623.

Hungr, O. \& Evans, S. G. (1997). A dynamic model for landslides with changing mass. Proceedings of the IAEG international symposium on engineering geology and the environment (eds $\mathrm{P}$. G. Marinos, G. C. Koukis, G. C. Tsiambaos and G. C. Stournaras), Vol. 1, pp. 719-724. Rotterdam: Balkema.

Hungr, O., Morgan, G. C. \& Kellerhals, R. (1984). Quantitative analysis of debris torrent hazards for design of remedial measures. Can. Geotech. J. 21, 663-677.

Jakob, M., Hungr, O. \& Thomson, B. (1997). Two debris flows with anomalously high magnitude. Proc. 1st Int. Conf. on Debris-flow Hazards Mitigation, San Francisco, 382-394.

Jakob, M., Anderson, D., Fuller, T., Hungr, O. \& Ayotte, D. (2000). An unusually large debris flow at Hummingbird Creek, Mara Lake, British Columbia. Can. Geotech. J. 37, No. 5, 11091125 .
Koch, T., Greve, R. \& Hutter, K. (1994). Unconfined flow of granular avalanches along a partly curved surface. II. Experiments and numerical computations. Proc. R. Soc. London, Ser. A 445, 415-435.

Korner, H. J. (1976). Reichweite und Geschwindigkeit von Bergsturzen und Fließschneelawinen. Rock Mech. 18, No. 6, 225256.

McDougall, S. \& Hungr, O. (2004). A model for the analysis of rapid landslide motion across three-dimensional terrain. Can. Geotech. J. 41, No. 6, 1084-1097.

McLellan, P. J. \& Kaiser, P. K. (1984). Application of a twoparameter model to rock avalanches in the Mackenzine Mountains. Proc. 4th Int. Symp. on Landslides, Toronto 1, 135-140.

McNeil, J., Taylor, C. \& Lick, W. (1996). Measurements of erosion of undisturbed bottom sediments with depth. J. Hydraul. Engng ASCE 122, No. 6, 316-324.

Nearing, M. A., Bradford, J. M. \& Parker, S. C. (1999). Soil detachment by shallow flow at low slopes. Soil Sci. Soc. Am. J. 55, No. 2, 339-344.

Rickenmann, D. \& Koch, T. (1997). Comparison of debris flow modelling approaches. Proc. 1st Int. Conf. on Debris-flow Hazards Mitigation, San Francisco, 576-585.

Roberts, J., Jepsen, R., Gottard, D. \& Lick, W. (1998). Effect of particle size and bulk density on erosion of quartz particles. J. Hydraul. Engng ASCE 124, No. 12, 1261-1267.

Sassa, K. (1988). Geotechnical model for the motion of landslides. Proc. 5th Int. Symp. on Landslides, Lausanne, 1, 37-55.

Savage, S. B. \& Hutter, K. (1989). The motion of a finite mass of granular material down a rough incline. J. Fluid Mech. 199, 177-215.

Tai, Y. C., Noelle, S., Gray, J. M. N. T. \& Hutter, K. (2002). Shock-capturing and front-tracking methods for granular avalanches. J. Comput. Phys. 175, No. 1, 269-301.

Takahashi, T., Nakagawa, H., Harada, T. \& Yamashiki, Y. (1992). Routing debris flows with particle segregation. J. Hydraul. Engng ASCE 118, No. 11, 1490-1507.

Tayfur, G. (2001). Modeling two-dimensional erosion process over infiltrating surface. J. Hydraul. Engng ASCE 6, No. 3, 259-262.

van Gassen, W. \& Cruden, D. M. (1989). Momentum transfer and friction in the debris of rock avalanche. Can. Geotech. J. 26, $623-628$.

Winterwerp, J. C. \& Kranenburg, C. (1997). Erosion of fluid mud layers. II: Experiments and model validation. J. Hydraul. Engng $A S C E$ 123, No. 6, 512-519.

Warburton, J., Higgitt, D. \& Mills, A. (2003). Anatomy of a Pennine peat slide, northern England. Earth Surface Processes and Landforms 28, No. 5, 457-473.

Zreik, D. A., Krishnappan, B. G., Germaine, J. T., Madsen, O. S. \& Ladd, C. C. (1998). Erosional and mechanical strengths of deposited cohesive sediments. J. Hydraul. Engng ASCE 124, No. $11,1076-1085$. 